\title{
Economic Impact of Category Captaincy: An Examination of Assortments and Prices
}

\author{
A DISSERTATION \\ SUBMITTED TO THE FACULTY OF THE GRADUATE SCHOOL \\ OF THE UNIVERSITY OF MINNESOTA \\ BY
}

Madhu Viswanathan

IN PARTIAL FULFILLMENT OF THE REQUIREMENTS FOR THE DEGREE OF

Doctor of Philosophy

George John \& Om Narasimhan

June, 2012 
(C) Madhu Viswanathan 2012

ALL RIGHTS RESERVED 


\section{Acknowledgements}

I am deeply indebted to my advisers Om Narasimhan and George John whose constant support, encouragement, guidance and great company made my $\mathrm{PhD}$ experience stimulating and enjoyable. I will never forget the countless hours I spent rehashing ideas with them.

I would also like to thank many people who made research in marketing interesting: Rajesh Chandy at London Business School and Mark Bergen for their enthusiasm and approach to research; Amil Petrin and Kyoo Il Kim from the economics program; Joe Redden, Akshay Rao, Deborah John, Rachel Shacham, Prokriti Mukherjee and other faculty members in the marketing program at the University of Minnesota for their sound input during the $\mathrm{PhD}$ program.

I am extremely grateful to my $\mathrm{PhD}$ cohort for making it a fun, exciting and creative environment. Nelson, my roommate of 5 years for tolerating my disorderliness despite his obsession towards all things clean and tidy, Paola, Noelle and Ranjan for being the people I could turn to during the difficult times, and Ryan and Janene for making time in the program fun. Paola was particularly helpful, acting as a sounding board for many of my research ideas. Sunil Kishore deserves a special mention for coaxing me into joining the $\mathrm{PhD}$ program at Minnesota.

$\mathrm{I}$ also wish to thank the staff in the marketing cluster and $\mathrm{PhD}$ program office ; Jill Johnson, Melissa Grass, Vicki Lund, Earlene Bronson, Elizabeth Lenzen and Bonita Bartholomew, for their assistance on numerous administrative tasks.

I am indebted to Brent Sherwin, Craig Crossley and Noah Houg for their crucial role in helping me obtain the data for this dissertation.

I would also like to thank my good friends, Arun Karthik, Shridhar Hegde, Karthikeyan and Srinivas for the emotional support, fellowship and fun times. 
I would also like to extend my gratitude to my mother, sister and late father. Their love and sacrifice have been a constant source of motivation. I would also like to thank my extended family for the support they provided to my family during the last five years.

Lastly, and most importantly, I would like to thank my wife, Poornima. She has been with me through the good and bad times, reoriented her life, shielded me from social responsibilities, provided emotional support during the tough times and done everything she could to bring this dissertation to fruition. The last six years have been a roller-coaster ride for both of us and this dissertation would not have been possible without her wholehearted support. 


\section{Dedication}

To my wife and the error term, both for their beautiful and mysterious ways. 


\begin{abstract}
Vertical arrangements like "Category Captaincy" and "Slotting fees" involve transactions on both price and non-price aspects (such as shelf-space allocations and assortments) and are becoming increasingly popular in retail markets. Given the financial scope and magnitude of the retail sector, such arrangements can have a disproportionately large impact on consumers and on the competitive landscape. Not surprisingly, they have been the subject of much scrutiny from industry practitioners and public policy experts. However, empirical work concerning these practices have been hampered by i) the difficulty in obtaining detailed data on these arrangements, and ii) the difficulty in developing models that can examine both price and non-price aspects of these arrangements, while accounting for horizontal competition between manufacturers and vertical interactions between manufacturers and retailers.

In this paper, I attempt to address the challenges above in the context of Category Captaincy, an arrangement where the retailer works exclusively with a manufacturer to manage both the manufacturer's and his rivals' products, and its impact on assortments and prices. I develop an empirical model of demand and supply to model assortment decisions under various category captain arrangements. I use a unique dataset for the frozen pizza category, that contains information on category captaincy across 20 retail chains and 5 local markets in the United States, in addition to retail movement data.

I discuss three potential welfare effects that occur under category captaincy. An efficiency effect occurs if captaincy lowers upfront cost per SKU compared to the retailer managing the category. A market-coverage effect occurs if captaincy leads to the addition of SKUs that a retailer would not have otherwise carried. Finally, a substitution effect occurs if captaincy leads to a rival's SKUs being dropped from the assortment carried. Together, these effects determine the products available to the consumers under captaincy arrangements.

My estimates point to an efficiency effect; on average, captaincy leads to savings of $\$ 2400$ per SKU per quarter for a retail chain. Further, I document evidence for market-coverage and substitution effects showing that captaincy leads to addition and/or deletion of SKUs that favor category captains and retailers at the expense of rival
\end{abstract}


manufacturers. Interestingly, captaincy can also lead to welfare gains for consumers, which argues against a purely negative view of captaincy by policy makers. 


\section{Contents}

\begin{tabular}{ll}
\hline Acknowledgements & i
\end{tabular}

Dedication iii

Abstract iv

List of Tables viii

List of Figures ix

\begin{tabular}{lll}
\hline 1 & Introduction & 1
\end{tabular}

$\begin{array}{lll}2 & \text { Relevant Literature } & 6\end{array}$

2.1 Category Management and Category Captaincy . . . . . . . . . . . . . 6

2.2 Vertical Restraints . . . . . . . . . . . . . . . . . . 9 9

2.3 Assortments . . . . . . . . . . . . . . . . . . . . . . . . . . . . . . . . . 11

$2.3 .1 \quad$ Assortment Research in Operations Management . . . . . . . . . 11

$2.3 .2 \quad$ Assortment Research in Marketing . . . . . . . . . . . . . . . . 12

2.4 Models of Assortment and Pricing . . . . . . . . . . . . . . . . . . 13

$\begin{array}{lll}3 & \text { Industry } & 15\end{array}$

3.1 Dataset . . . . . . . . . . . . . . . . . . . . . 16

3.2 Summary Statistics $\ldots \ldots \ldots \ldots \ldots \ldots$

\begin{tabular}{|lll}
\hline & Model & 22
\end{tabular}

4.0 .1 Consumer Demand . . . . . . . . . . . . . . . . . . . 23 


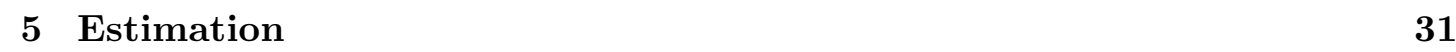



\begin{tabular}{lll}
\hline 7 & Counterfactuals & 39
\end{tabular}

8 Conclusion and Discussion 43

\begin{tabular}{|ll|}
\hline 9 & References
\end{tabular}

\begin{tabular}{|l|l|}
\hline Appendix A. Tables \& Figures & 53
\end{tabular}

A.1 Descriptive Statistics . . . . . . . . . . . . . . . . . . 53

A.2 Demand Results . . . . . . . . . . . . . . . . . . . . . . 59 


\section{List of Tables}

A.1 Variable Description and Descriptive Statistics . . . . . . . . . . . 53

A.2 Descriptive Results by Markets . . . . . . . . . . . . . . . . . . 55

A.3 Reduced Form Results - Brand Level . . . . . . . . . . . . . . . . . . . . 56

A.4 Reduced Form Results . . . . . . . . . . . . . . . . . . . . . 57

A.5 Chain 1: Captaincy Change from Firm A to Retail management . . . . 58

A.6 Chain 2: Captaincy Change from Firm B to Firm A . . . . . . . . . 58

A.7 Demand Results - Baltimore Market . . . . . . . . . . . . . . . . . 59

A.8 Demand Results - Boston Market . . . . . . . . . . . . . . . . . . . 60

A.9 Demand Results - Erie Market . . . . . . . . . . . . . . . . . . . . . 61

A.10 Demand Results - Las Vegas Market . . . . . . . . . . . . . . . . . 63

A.11 Demand Results - Los Angeles Market . . . . . . . . . . . . . . . . . . . 64

A.12 Demand Results - New York Market . . . . . . . . . . . . . . . . . . . . 65

A.13 Demand Results - Poughkeepsie Market . . . . . . . . . . . . . 67

A.14 BLP estimates, cost parameters for Baltimore Market . . . . . . . . . 68

A.15 Inequalities Analysis Results . . . . . . . . . . . . . . . . . 69

A.16 Counterfactual Analysis for Baltimore Market . . . . . . . . . . . . . . . 71 


\section{List of Figures}

A.1 Distribution of MSAs. . . . . . . . . . . . . . . . . . . 72

A.2 Distribution of captaincy $\ldots \ldots \ldots \ldots \ldots \ldots \ldots \ldots$

A.3 Distribution of captaincy by chain size $\ldots \ldots \ldots \ldots \ldots \ldots$

A.4 Distribution of captaincy by chain size $\ldots \ldots \ldots \ldots \ldots \ldots$

A.5 Distribution of captaincy by chain size $\ldots \ldots \ldots \ldots \ldots$

A.6 Chain Revenues by captaincy . . . . . . . . . . . . . . . . 77

A.7 Distribution of Market shares . . . . . . . . . . . . . . . . . 78

(a) Distribution of Firm A's Market Shares … . . . . . . . 78

(b) Distribution of Firm B's Market Shares . . . . . . . . . . . . . . . . . 78

A.8 Distribution of Assortment shares. . . . . . . . . . . . . . . . . . 79 


\section{Chapter 1}

\section{Introduction}

Intensive price competition, new advances in technology, and highly demanding consumers are forcing retailers to enter into innovative arrangements with manufacturers to improve profit margins. One such arrangement that has become increasingly popular in the food and drug retail industry, ranging from slow-moving categories like hair and skin care products to fast-moving categories like fresh produce (Progressive Grocer, 2010) is Category Captaincy.

Category Captaincy is an arrangement between a retailer and a manufacturer in a category, wherein that manufacturer influences category decisions for all the products (both his and his rivals) (Desrochers et al. 2003). The category captain may also assist in analyzing, developing and implementing category plans 1 . Manufacturers who act as category captains may often pay the retailers for this privilege, directly and/or indirectly by shouldering the costs of managing the category, e.g., by allocating personnel and money to the task (FTC 2001$)$.

Despite the widespread prevalence and importance of category captaincy, research on the topic remains sparse and has largely been limited to theoretical analysis (Subra-

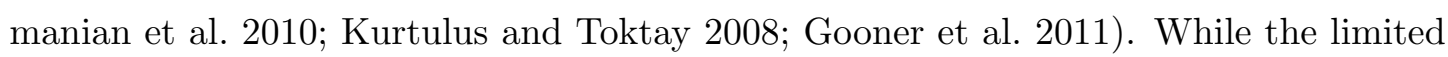
theoretical work has improved our understanding of these arrangements, the question of whether category captain arrangements are on balance, pro- or anti-competitive is still open to debate. Indeed, a Federal Trade Commission (FTC) chaired academic panel

1 The identity and extent of the category captain's role varies. In general, retailers appoint one of the manufacturers to be the category captain. 
called for further empirical evidence and fact-based research to help public policy makers and industry practitioners better understand category captain effects (HerderscheeHunter 2003). Understandably there is concern ${ }^{2}$ (Gruen and Shah 2000 Lindblom and Olkkonen 2008; FTC 2001) that category captains can use their special status with retailers to significantly affect the pricing and availability of products on the shelf, undermine competition and consequently hurt consumers. Further, understanding the nature of category captain arrangements is critical to manufacturers in devising competitive strategies, and to policy makers interested in understanding the welfare effects of such arrangements. My research advances the insights developed in previous research by empirically studying the impact of category captain arrangements on manufacturers, retailers and consumers. In particular, I address the following questions: i) Does the category captain reduce the overall assortment of products? ii) Do category captains selectively alter the assortment to favor their own products over those of their rivals? iii) Do retail prices increase or decrease under category captaincy? iv) Does social welfare increase or decrease under category captaincy?

There are several challenges to overcome. First, to empirically assess captaincy arrangements, one requires data on how the market differs under captaincy and without. However, detailed data with sufficient variation on both supply side arrangements and demand is not readily available $3^{3}$ Second, even with sufficient data, empirical analysis is difficult because many aspects such as the payments between manufacturers and retailers are typically not observed. The challenge then is to recover these payments from observable measures of market structure and demand. This requires both a rich demand model that captures variation in consumer preferences and a supply model of both assortment and prices that embeds the horizontal interaction between competing

\footnotetext{
2 In an antitrust case, Conwood Co. v. United States Tobacco Co. 290 F3d 768 (6th Cir 2002), cert denied, 537 US 1148 (2003), the Supreme Court held that United States Tobacco abused its category captaincy status in the chewing tobacco category and awarded $\$ 1.06$ Billion in damages, one of the largest verdicts in anti-trust history.

3 The most straightforward way to evaluate the effect of category captaincy would be to design experiments with a random assignment of arrangements. For obvious reasons, it is unlikely that profit maximizing manufacturers and retailers will permit such a random assignment to happen in the real world. The next best alternative is to use "natural experiments" that occur due to changes in regulations allowing us to distinguish between a "treatment group" where these arrangements are observed and a "control group" that is not affected. This approach however limits the scope of arrangements that can be studied to those directly affected by the change in regulations. Absent these changes, one is forced to use cross-sectional or panel data to understand the impact of these arrangements.
} 
manufacturers and vertical interactions between manufacturers and retailers. Finally, there are methodological challenges unique to simultaneously modeling assortments and price (Misra 2008). For one, typical retail assortments in this category of study contain an average of 60 products and the large number of options available to choose from makes this problem ${ }^{4}$ mathematically daunting.

I quantify the costs and benefits of category captaincy on retailers, category captains, rival manufacturers, and consumers. I focus on retail assortments and prices. While price is obviously important, my focus on assortments deserves some explanation. Category management involves aspects such as shelf space management, stocking, and assortment selection (also known as "category reset"). Besides being one of the more important category management decisions (Gajanan et al. 2007; Misra 2008), my choice of assortment is governed by institutional reasons. The category that I have chosen to examine is dominated by manufacturers who use a Direct-Store-Delivery (DSD) distribution systems. In a DSD system, stocking and shelf-space management are largely left to the manufacturer. My focus on assortment carries the happy side benefit of helping differentiate my work from most prior research that has focused only on price. Asker 2004; Brenkers and Verboven 2004). This is an important advance, because improvements in non-price elements can lead to higher prices that can be misinterpreted to imply anti-competitive motives. Finally, while I restrict my current analysis to assortment and pricing decisions, my framework is flexible enough to be extended to other contexts.

I discuss three potential welfare effects that occur from moving to a category captain arrangement, a "market-coverage effect", an "efficiency effect" and a "substitution effect." Manufacturers, especially the larger ones, have needed expertise regarding the category and possess capabilities in managing a category (Desrochers et al. 2003; Leary 2003). An efficiency effect occurs if the shift to a category captain arrangement lowers upfront cost per SKU compared to the retailer managing the category. A marketcoverage effect occurs if the move to category captain arrangements lead to the addition of SKUs that a retailer would have otherwise not carried. Finally, a substitution effect occurs if the shift to category captaincy arrangement leads to a rival's SKUs being dropped from the assortment carried. Together, these effects determine the products

\footnotetext{
4 The number of possible assortments, from an option set of 60 products, is $2^{60}-1$
} 
available to the consumers under category captain arrangements.

I build a structural model that accounts for key institutional features. I draw on a unique dataset that contains, in addition to SKU-store-level movement data such as unit sales and prices, information on category captain arrangements across 24 retail chains in the United States in the frozen pizza category from March 2010 - December 2011. Crucially, I observe variation in category captaincy across chains. My structural model consists of three parts: i) a demand model that allows for heterogeneity in preferences, ii) a pricing model that allows for competition between manufacturers, and iii) an assortment decision model that captures differences in decision making between a retailer and a category captain. The focus of the demand model is to capture the impact of adding or removing a SKU from the consumer choice set on consumer preferences for all the products offered by the retailer. The demand estimates combined with familiar assumptions on pricing are used to recover the marginal costs for every product. The role of the pricing model is to capture the pricing response to changes in the assortment. Finally, the assortment model explicitly focuses on the assortment choice itself. All three components together allow me to estimate unobservable factors of interest, such as consumer preferences, marginal and fixed costs. I use these estimates to answer, counterfactually, how a market currently without a category captain arrangements would change if category captaincy was instituted. In addition to looking at the number of SKUs and the ownership mix of these SKUs, I also predict prices and conduct a welfare analysis under the new regime.

My results show a strong efficiency effect: under category captaincy, the cost of adding a SKU to the assortment carried in a store is $\$ 2400$ less than without a category captain. Further, I find that category captain arrangements always lead to the introduction of SKUs that the retailer would not have otherwise carried, evidence for the market coverage effect. In addition, I also find that under category captaincy, the SKUs included in the assortment favor the captain, which is the substitution effect defined earlier. Retailers always seem to benefit from the category captain arrangement while not all manufacturers gain. In general, the "efficiency effect" seems to dominate any losses that might have been incurred due to the "substitution" effect. Overall, I find that the shift to category captaincy is surplus improving for the channel while it might not be so for each individual actor. 
To the best of my knowledge, this is the first paper that empirically examines the role of category captain arrangements, and quantifies their impact on consumers and various channel actors. My paper is relevant to academics who study related vertical ties such as exclusive dealing and slotting allowances. Prior empirical studies have primarily focused on the role of price in these manufacturer-supplier arrangements, but my research is the first to isolate the impact on price and non-price (assortments) aspects. Methodologically, my study adds to the small body of work in marketing that seeks to structurally estimate the parameters of both assortments and pricing decisions (Draganska et al. 2008; Misra 2008). I use a new inequalities-based estimator to capture the unobserved parameters while accounting for the rich institutional complexities inherent in channel relationships. Managerially, my research is of importance to manufacturers and retailers in understanding the costs and benefits of these vertical arrangements. Policy makers are scrutinizing many of these manufacturer-supplier arrangements for possible threats to competition, particularly consumer welfare reductions arising from an increase in retail prices or a reduction in SKUs. In this regard, my toolkit can be employed by policy makers.

The remainder of this paper is organized as follows: In Section 2 I discuss the literature related to the research. In Section 3, I describe the empirical context and data used in the empirical analyses. Sections 4 and 5 address the econometric models and results. Finally, Section 6 offers conclusions and ideas for future research. 


\section{Chapter 2}

\section{Relevant Literature}

I review four related streams; the literature in marketing on category management $(\mathrm{CM})$ and category captaincy, the work on vertical restrictions in the economics and management literatures, the research in marketing and operations on assortments, and the empirical work on modeling assortments and prices.

\subsection{Category Management and Category Captaincy}

CM refers to a process of managing individual product categories as a whole (Blattberg and Fox 1995). In contrast to brand or vendor oriented management, CM processes are cognizant of the mutual relationship between products within the category and focus on entire product categories rather than on individual brands (Basuroy et al. 2001) while making decisions on pricing, assortments, shelving and merchandising. The underlying notion behind the CM philosophy is asset management (McLaughlin and Hawkes 1994). This involves analyzing category level data and allocation of scarce resources across products within the category to leverage assets such as shelf-space, customer traffic etc.

While CM has been practiced for well over two decades and is very popular, especially in the Consumer Packaged Goods (CPG) industry, most retailers lack the resources and capabilities to implement category management efficiently (Morgan et al. 2007) in all the categories. On the other hand, manufacturers have developed the expertise for efficient assortment planning, pricing and promotions. This has consequently lead to greater cooperation between manufacturers and retailers in implementing category 
management, by bringing in their insights on consumer and market trends. A special form of category management is category captaincy, where one designated manufacturer works with the retailer to manage the category (Subramanian et al. 2010).

In a captaincy arrangement, the designated manufacturer (captain) undertakes joint responsibility with the retailer for developing and growing the category. The captain is provided access to proprietary sales information for the entire category by the retailer in exchange for developing a category plan that encompasses all the SKUs in the category including that of its rivals. The captain combines the data provided by the retailer with his/her category management expertise to provide specific recommendations on growing the category. These recommendations include listing/delisting of SKUs, shelffacing allocations and shelf placements of various SKUs in the category Gruen and Shah 2000).

Captaincy is now gaining widespread traction among retailers (Subramanian et al. 2010) with some experts including the FTC suggesting that retailers can ramp up their CM efforts and benefit from the manufacturer's superior expertise in the category. The general assumption is that by leveraging manufacturers expertise, retailers can improve the performance of the category, subsequently benefitting all the channel actors (manufacturers and retailers) in the category. This is supported by anecdotal reports of success by retailers and manufacturers who have implemented category captaincy (Progressive Grocer 2007, 2008). However, this practice has raised other concerns. First, retailers and policy practitioners are wary that captains might indulge in opportunistic behavior that might lead to decisions that favor captain's products over those of rivals. Second, public policy practitioners are concerned that this arrangement might lead to collusion between retailers through a "hub-spoke" kind of mechanism (Desrochers et al. 2003; Steiner 2000; Leary 2003). Despite the fact that captaincy is an important but controversial practice for manufacturers, retailers and public policy practitioners, there is very limited research on captaincy.

Most of the current research on captaincy is based on game theoretic analytical models. Kurtulus and Toktay (2011) examine category captaincy wherein pricing decisions are delegated to category captains under limited shelf space. Their model consists of two manufacturers selling to a consumer through a single retailer. They show that retailers can use captaincy arrangements and shelf space to control the intensity of competition 
between rival manufacturers to benefit themselves. Emergence of captaincy arrangements depends on the degree of product differentiation, opportunity cost of shelf space and profit sharing arrangement between the retailer and the captain. They find that these arrangements are in general disadvantageous to captain's rivals, but benefit the rivals when the category captain arrangement is implemented by a powerful retailer. Misra et al. (2009) examines the selection of category captains and how this selection impacts profits. Similar to the Kurtulus and Toktay (2011), retailers delegate pricing to the captain arrangement. He shows that retailers choose small as well as large manufacturers to be the category captain depending on the circumstances.

While the previously mentioned papers on category captain focus on price as the main decision variable, Subramanian et al. (2010) examine the impact of category captain arrangements when the category captain is responsible for providing non-price services that can enhance demand (e.g. shelf space design allocations or managing endof-aisle displays). In their analytical model, manufacturers compete to become category captains and provide two types of service - a category enhancing service that increases the demand for both the category captains' and their rivals' products, and a share enhancing service that increases the demand for only the category captains' products. Using this setup, they show that brand substitutability creates a service efficiency effect, i.e., category enhancing services are more effective in increasing manufacturer's sales and profit margins than are services that shift demand from a rival's brand. Kurtulus and Nakkas (2011) examine the consequences of using captaincy for assortment selection decisions. They build an analytical model where captains or manufacturers have information on consumers that retailers do not possess, and show that captaincy can be profitable for all players (retailer, captain, rival manufacturer). In contrast to the analytical studies, Gooner et al. (2011) use a combination of surveys, category and financial growth data to show that using a captain increases category management efforts without increasing opportunism or problems with other suppliers. They also find that retailers with more resources are less likely to rely on help from a category captain.

My dissertation is different from the current studies on category management and captaincy on two important dimensions. One, it is an empirical study. Despite these practices being around for decades, there is very limited empirical work on category management (Dhar et al. 2001, Gruen and Shah 2000) and captaincy (Gooner et al. 
2011). My research develops a model of captaincy that integrates both supply and demand data from a representative sample of U.S supermarket chains to quantify the pros and cons of captaincy. Second, my research investigates the impact of captaincy on assortment selection decisions. This is in contrast to most other work on captaincy which focuses on price. In that regard, my work complements the analytical work by Subramanian et al. (2010) and Kurtulus and Nakkas (2011) by empirically examining a non-price service (assortment selection) offered by the manufacturer. Besides being an empirical model, my model differs from the above two papers in that it does not rely on two different types of service or informational advantages to capture the impact of category captain arrangements. To the best of my knowledge, my work is the first empirical examination of the impact of category captains in both price and non-price contexts.

\subsection{Vertical Restraints}

A "vertical restraint" is defined as any arrangement that imposes restrictions between upstream manufacturers and downstream retailers (Lafontaine and Slade|2005). Vertical restrictions have been the subject of much research, with two dominant and themes emerging over the years: i) the efficiency stream, which extols the virtues of these relationships, focusing on the reduced prices and increases to consumer welfare due to increased competition, and ii) the foreclosure stream, which focuses on the threats to competition due to such arrangements and the resulting drop in consumer welfare (see Lafontaine and Slade (2005) for a review).

Category Captaincy can be viewed as a vertical restraint because it involves an arrangement between the manufacturer and retailer. However, this view is not supported by all observers. This is because captains may affect competition between the brands (inter brand) in a category through his advice to the retailer. While courts in general have recognized that manufacturers have the right to restrain practices at the retail level to rationalize intrabrand competition, captaincy arrangements present a more complicated picture because captains provide advise on their (intrabrand) and their rivals' (inter brand) products. While acknowledging the complexity in classifying this practice as a vertical restraint, I do so based on the current legal treatment of these practices. 
From an anti-trust point of view, analyzing the impact of captain's conduct requires examination of its harmful and beneficial effects on competition and consumers. This includes the impact of captaincy on the incentives and abilities of rival manufacturers to compete in the defined market. Consumer outcomes like price, variety and choice are also relevant. It is understood that some harmful conduct might still have the ability to contribute positively in the form of "efficiencies" leading to beneficial effects for consumers. Assessing the overall impact thus requires balancing the harms to competition and consumers with the benefits. If the harms outweigh the benefits, the practice is considered to be anticompetitive and harmful to consumers.

The arguments for the pros and cons of captaincy are as follows. CM is generally considered to reduce marketing and distribution costs. Captaincy allows retailers to leverage the benefits of CM through the expertise of informed captains. Supporters of the practice contend that manufacturers, especially bigger manufacturers, possess better information and resources regarding the category they compete in than retailers. Retailers, being less well-informed than manufacturers can thus benefit from the assistance.

Concern for the role of captains comes from the decision control that captains possess. The distinctive feature of captaincy arrangements is the ability of captains to provide recommendations for the entire category. While such inputs might benefit the category and consequently competition through cost savings and other benefits, such arrangements also provide ample opportunities for affecting competition through selfinterest conduct. This potential for opportunistic conduct is heightened by the conflict of interest inherent in the captain's role. While the captain is required to provide input that helps the retailer, he/she is also responsible for his/her firm's interest. As Desrocher et al. (2003) note, the information-based nature of captaincy arrangements can lead to opportunistic behavior that are subtle and based on bias, incompleteness, distortion, manipulation and other means. In summary, the complex vertical and horizontal aspects of captaincy, the management of information and providing advice to the retailer by a captain suffering from conflict of interest lead to two primary antitrust concerns 1) disadvantaging competitors, leading to competitive exclusion and 2) coordinating competitive behavior through competition collusion.

In this research, I analyze the impact of captaincy arrangements by quantifying the 
costs and benefits of captaincy on captains, rival manufacturers, retailers and consumers. In that regard, I provide a model that assess, whether, on balance, the benefits from captaincy outweigh the harms. Further, my research is the first empirical test of this practice, thereby providing researchers and public policy practitioners valuable evidence of this practice.

\subsection{Assortments}

There is a substantial amount of literature on assortment planning in the marketing, operations management. This is not surprising given the importance of assortment planning (Basuroy et al. 2001; Misra 2008) to retail category management. This literature on assortment planning considers the question of which and how many different products to offer (Mantrala et al. 2009). For ease of exposition, I divide the literature survey in two parts 1) assortment research in operation and, 2) assortment research in marketing.

\subsubsection{Assortment Research in Operations Management}

The operations literature seeks to establish the optimal inventory levels for an assortment (see Kok et al. 2006 for a review). Van Ryzin and Mahajan (1999) study a static assortment planning approach, where the demand derives from stochastic choice processes in which individual purchase decisions are made according to a multinomial logit model. They show that the number of assortments to be considered reduces from $2^{n}$ to $n$. Several papers have extended the van Ryzin-Mahajan model by relaxing various assumptions. For example, Cachon et al. (2005) incorporate consumer search costs to show that an unprofitable product may nevertheless be carried within the assortment. Maddah and Bish (2007) also extend the van Ryzin-Mahajan model by incorporating the pricing decisions, into the assortment problem. They show that the simple ranking rule from Van Ryzin-Mahajan holds as long as the marginal costs are non-increasing. In general, the class of models that use the van Ryzin-Mahajan model as a starting point show that products can be arranged by their popularity and the most popular products are in the assortment. While these papers capture the trade-off between variety and

increased average inventory costs, the main assumption regarding homogenous group of 
products with identical costs is quite restrictive. The result is especially problematic in light of the fact that wholesale prices are likely to be higher for popular products. My modeling framework allows for differences in marginal costs and demand.

Another stream in the operations literature considers the assortment problem using an exogenous model of demand (Cachon and Kok 2007; Kok and Fisher 2007). Exogenous demand models directly specify the demand and substitution patterns for each product in the assortment. The general conclusion is that products with higher margins (or demand) have higher shelf space. While exogenous demand models are more flexible than the Van Ryzin-Mahajan models (Kok et al. 2006; Mantrala et al. 2009), they abstract away from the economics of the problem by ignoring retail competition and price.

I follow the Empirical Industrial Organization (EIO) paradigm. According to this paradigm, the observed data is an equilibrium outcome of strategic interactions between various players (in this case, retailers and manufacturers). As Misra (2008) points out, the EIO approach is conceptually different from that followed in the operations literature. I explicitly account for endogenous price and assortments while modeling the demand for products.

\subsubsection{Assortment Research in Marketing}

The salience of assortments in consumer decision making can be readily seen by the numerous studies in marketing on this issue (see McAlister and Pessemier (1982) for a review). Consumers' perceptions of variety has been shown to be influenced by space allocated to the product, presence or absence of consumers' favorite items Broniarczyk et al. 1998), arrangement of assortments and variety in attributes offered (Hoch et al. 1999, 2002). From a supply perspective, variety is costly to offer because a broader assortment implies less demand, which can lead to higher inventory and handling costs. Thus the optimal mix of products in an assortment depends on both demand and supply factors. In this paper, I account for assortment variety based on how it influences both supply and demand.

A small stream of the behavioral marketing literature examines the impact of assortment reductions on consumer retention. This literature argues that giving consumers a larger choice set confuses them leading to lower purchase probabilities (Chernev 2003 , 
2006: Iyengar and Lepper 2000). However, Boatwright and Nunes (2001, 2004) and Sloot et al. (2006) find no change or an increase in category sales after a reduction in assortment, while Borle et al. (2005) find that a one time reduction in assortment across all categories reduces overall store sales. Furthermore, the Borle et al. (2005) suggests that the impact of assortment reduction varies by the purchase frequency of categories with more frequently purchased categories being less impacted by the reduction.

\subsection{Models of Assortment and Pricing}

My approach is closest to the work on endogenous product choices and pricing (Yurukoglu and Crawford 2011; Eizenberg 2009, Draganska et al. 2008; Misra 2008). As is well known, these models have to account for multiple equilibria that arise in these contexts (for an illustration of the multiple equilibria problem in assortments, refer to Draganska et al. 2008). The empirical challenge is to identify the equilibrium that is being observed and subsequently estimate the parameters that satisfy the observed equilibrium. There are two extant approaches, one is to assume private information between actors which leads to the existence of a pure strategy Nash Equilibrium (e.g., Seim 2006; Draganska et al. 2008). The second strategy is to use a selection procedure which ensures that a pure strategy Nash equilibrium is observed (Misra 2008). While multiple equilbria is not a concern in my case, I rely on an estimation procedure that accommodates multiple equilibria without requiring equilibrium selection to estimate unobserved parameters.

Endogenizing assortment decisions also complicates estimation of demand parameters. Random coefficient models of demand based on Berry et al. (henceforth BLP) (1995) assume that any change in product offering is exogenous, and is therefore uncorrelated to demand and supply. Endogenizing the assortment decision essentially relaxes this assumption by modeling the decision of firms to select certain products in this assortment (Misra 2008). In other words, the set of product choices available to the consumers is not random any more. Prior literature has tackled this selection problem by choosing alternate demand systems that do not exhibit this problem ${ }^{1}$. Draganska et

\footnotetext{
1 A rare exception to this approach is Yurukuglu (2011) who examines bundling choice decisions in the Cable TV market. Because of his unique context, he is able to account for the selection mechanism by directly incorporating it into the model
} 
al. (2008) study different varieties of vanilla ice cream introduced into different markets. Their demand model, assumes that there is no unobserved heterogeneity in preferences for the product and no unobserved demand shocks. In addition, their modeling approach requires one to evaluate all possible assortment choices, i.e., in a category with $n$ products, one has to evaluate $2^{n}$ combinations which becomes intractable rapidly. Misra (2008) uses an assortment selection process that reduces the computational load of the model. He is able to include unobserved demand shocks but does not incorporate unobserved heterogeneity. In this paper, I employ a demand system that incorporates both unobserved heterogeneity and unobserved demand shocks to the system.

Another important difference between my model and previous literature on firm choice is the focus on a complex arrangement such as category captaincy. While most of the existing literature has focused on the decisions made by either manufacturers or retailers, my research question requires me to model the behaviors of category captain, competing manufacturers and retailers. Although the problems are conceptually similar, considering the interactions between the manufacturer and retailer adds an additional layer of complexity. I use an inequalities estimator (Pakes et al. 2006) in which either category captains or retailers choose assortments conditional on their expectations regarding other assortment choices and prices for the chosen assortment. This methodology is particularly useful for solving discrete choice games, where uniqueness of equilibrium is not guaranteed. Based on the "revealed preference" approach, the model identifies a set of moment inequalities which place bounds on the parameters. Recent work in empirical industrial organization has used this approach to examine fullline forcing contracts in the video game industry (Ho et al. 2011), HMO networks in healthcare (Ho|2009), and exclusive dealing in the video game console market (Lee 2009). The discreteness of the assortment choice problem, problems of multiple equilibria and the combinatorial complexity of the assortment problem all make this methodology indisputable for my research. In the next section, I outline my empirical context following which I describe my model and estimation procedure. 


\section{Chapter 3}

\section{Industry}

The frozen pizza 11 category is the third largest section in the frozen food department and had over $\$ 3$ billion in sales in 2010. It is also one of the fastest growing categories in terms of space and is projected to grow $26 \%$ by 2015 (AC Nielsen 2010).

Schwan's and Nestle 2 account for almost $75 \%$ of dollar sales in this category. Other manufacturers include General Mills, Palermo Villa, and Amy's. Private labels accounts for about $11 \%$ of total sales volume.

Frozen pizza is segmented into three sub-categories based on the quality of the ingredients that go into the pizza - regular (e.g., the Tombstone brand), premium (e.g., DiGiorno, Freschetta), and value (e.g., Tony's, Jack's). Of these, the premium subcategory is the largest in terms of sales and variety of products. California Pizza Kitchen, Freschetta and DiGiorno are the major brands in this sub-category.

The frozen pizza category offers several advantages as a context to study category captaincy. First, the product attributes that consumers care about are easy to characterize. In addition to price, consumers care about crusts and toppings. Crusts may be thin or thick, with self-rising and hand-tossed being variations of the thick crust. The popular pizza toppings are pepperoni, sausage, meat like canadian bacon, and cheese although speciality toppings such as vegetarian, Mexican, etc. are also gaining in popularity (Holcomb 2010). Knowing these details enables me to specify a detailed demand

\footnotetext{
1 The term "frozen pizza" includes all types of frozen pizza except bite-size snacks and "breakfast pizzas"

2 Nestle took over Kraft's frozen pizza category in 2010
} 
system for consumer preferences over these attributes. Second, the major firms in this category use a Direct-Store-Delivery (DSD) distribution system to distribute their pizzas. In a DSD system, individual manufacturers handle delivery, inventory and stocking of their products. Retailers therefore do not incur any costs for carrying frozen pizzas beyond the costs of refrigeration. As such, captains have minimal impact on the inventory and stocking decisions of competing manufacturers. This to a large extent justifies my emphasis on assortment planning (shelf-reset) as the core of category captaincy in this category $\left.\right|^{3}$.

\subsection{Dataset}

I assembled a unique dataset for this study from two different sources. I obtained store-level movement data from AC Nielsen Storeview database for to 24 major retail chains across 7 different regions of the U.S. These data exclude discount retail chains like Walmart and Target. The markets are centered around major cities in the US, such as Los Angeles, Baltimore, etc 4 See Table A.2 for a description of the markets. In each of these markets, I observe monthly store-level data for 21 months from March 2010 through Dec 25, 2011. The data include price and units sold of every SKU in each week at each store. In addition, I observe detailed product attribute information, such as toppings and crust type for every SKU. On the supply side, I have information on the category captain for all the retail chains at each point in time ${ }^{6}$. This translated to category captain information on roughly 4 chains per market. Category captaincy decisions are generally made once every 2 years or more. While I do observe a changes in captaincy for a few chains, these are not sufficient to tease out interaction effects between chain and captaincy arrangement: 7 in my data.

I compute the market size for a chain the following way. For each store, I obtain the

\footnotetext{
3 Evidence that category captains play an influential role in assortment decisions comes from articles in the trade press (Progressive Grocer 2010 and interviews with category captains in this category

4 While the data cover most major cities, there are notable exceptions, e.g., we do not observe stores in Chicago.

5 Most retailers have make one major reset decision during March. Our choice of time period was predicated on this factor

6 This data was obtained from a manufacturer who wishes to keep his identity confidential.

7 My discussion with industry leaders also revealed that category captain decisions are very sticky in nature.
} 
total number of households in the metropolitan statistical area that the chain belongs to. I then multiply it with the percentage share of the chain to obtain the market size for each chain.

Next, I examine the assortment for the premium pizza category. There are 138 unique SKUs in this category with the major manufacturers being Nestle and Schwan's. The main brands in this category are Freschetta, California Pizza Kitchen, Digiorno's, and Amy's. Given my interest in understanding category assortment decisions, the focus on a subcategory of the frozen pizza category would be problematic if category managers maximize profits by category and not by subcategories. However, my conversations with industry practitioners suggest that decisions in this category are made at the subcategory level. I further restrict my attention to SKUs that account for the top $90 \%$ of a market's sales and volume in this category. This roughly translates to 70 SKUs per market, which I denote as the superset. Chains pick SKUs for their assortments from this superset. Table A.2 describes the variation across chains in assortments by market. On average, chains stock around 50 SKUs of the total 70 SKUs, with variation across chains on the types of SKUs selected.

Given the centrality of assortment decisions to my model, it is important to explicate how I measure assortments. A SKU is denoted as part of the assortment in a given chain and time period if a SKU's sales are nonzero. To avoid situations where a SKU is on the shelf but records zero sales, I aggregate the data to the quarterly level (Misra 2008). While aggregating the data, I ensured that I do not lose any monthly variation in assortments. Recall the assortment in a chain comes from a superset of products that are currently available for the market. I assume that this superset is the union of all products sold at any chain for a particular market. This assumption is problematic if my dataset does not include data from chains which are an important part of the assortment mix. For example, the assortment superset for Los Angeles is likely to be biased if I do not have information about the assortments carried by the Albertsons chain. However, the movement data that I possess contains sales information for all the major chains in a particular market, which allows me to adequately capture the variation in assortments across chain: 8 .

\footnotetext{
8 My objective in this paper is to examine the impact of category captains on assortments and prices. While competition between stores/chains may also influence observed assortments and prices, I do not explicitly model chain-store choice and retail competition. The choice of which chain-store to
} 
Turning to further details of the premium category, note that Digiorno's is the market leader, accounting for almost $40 \%$ of sales volume, followed by Freschetta and California Pizza Kitchen. Descriptive statistics for the different attributes given in Table A.1 show Crispy crust is the most popular crust type in this category. Popular toppings include cheese, vegetable and pineapple. Average prices range from $\$ 5$ for Digorno's and $\$ 7$ for Amy's.

\subsection{Summary Statistics}

Before I proceed to model the behavior of these actors, I present descriptive statistics, regressions and case studies that suggest captaincy arrangements indeed affect performance in this category. To do so, I leverage the variation in captaincy arrangements, category sales, brand sales, price and assortments across chains and time. For the sake of confidentiality, I shall henceforth refer to the leading manufacturers as Firm A and Firm B.

The data presents a few interesting trends with respect to the distribution of captaincy across chains. First there is a significant correlation between chain size and captaincy. A.3 and A.4 show the variation in captaincy by different measures of chain size (average store size, number of stores in chain and a composite score index). Captaincy arrangements are found to occur in chains which are bigger in size. This makes sense given that bigger chains are more likely to have resources that can leverage captain's expertise on category management better than smaller chains. Further, from the manufacturer's point of view the marginal gains from captaincy arrangements is likely to be higher in bigger chains. Not surprisingly, chains with captaincy also on an average tend to have higher category sales and carry more SKUs than non-category captains A.6. While some it may be attributable to the differences in chain size, A.5 shows variation in assortment sizes among similar size firms suggesting that size may not completely explain variation in assortment size.

To highlight the role of captaincy on captains and rival manufacturers, consider the case when Firm A is the captain. Figure A.7 shows that market share for Firm A,

shop at is a complex decision which depends on the overall number of categories and variety offered in a particular retail chain. Unfortunately, I do not have data for any other category to model this decision process. I accommodate chain and retail competition indirectly in determining the market size. 
goes up while that of Firm B goes down under Firm A's captaincy. Most of difference in market shares arises from differences in assortments (i.e., number of SKUs carried) by chains with captaincy and those without. Figure A.8 shows the distribution in assortment shares (defined as total number of manufacturer SKUs/total number of SKUs in category ${ }^{9}$ ) across captaincy arrangements. Once again note that Firm A stocks more of its SKUs under its captaincy. Segmenting the products based on a median split of retail prices reveals that these additional SKUs are primarily lower retail priced SKUs belonging to the captain. Finally, as far as prices are concerned, I find that the average price for the captain's products goes down while that of the noncaptain goes up. These differences arise due to two reasons: i) introduction of lower priced captains' SKUs which drives their average prices down, and ii) introduction of more SKUs to the assortment mix which also reduces prices. Figures A.7, A.8 show similar trends for Firm B as captain. In sum, these facts suggest that chains with captaincy a) are larger, b) tend to have higher category sales and larger assortments and, c) carry a disproportionately bigger portion of captain's SKUs. Next, I try to provide a more systematic picture by estimating a reduced form model of captaincy on sales, assortment and prices.

The main goal of this analysis is to relate the variability in brand performance across retail chains to captaincy arrangements while controlling for brand characteristics, chain characteristics, pricing, merchandising support, advertising and consumer promotion. To answer this performance question, I consider a specific performance measure called Brand Development Index or BDI, which is sometimes also referred to as fair share analysis. This measure has a long history in the packaged goods industry and is used to measure the relative brand performance of a retailer. The index for brand $j$ in retail chain $i$ is defined as:

$$
B D I_{i j}=\frac{\text { Retailer }_{i} U_{\text {nitVolumeinBrand }}}{\text { MarketUnitVolumeinBrand }_{j}} X \frac{\text { TotalMarketVolume }_{\text {TotalRetaileriVolume }}}{\text { Told }}
$$

In words, a retailer's BDI for a brand is calculated as the ratio of its share of the

\footnotetext{
9 This measure of assortment share accounts for differences in number of assortments carried based on size of store. Assortment variety can also be measured based on breadth (number of different brands carried) and depth (number of SKUs of each brand). My measure is more closely related to the depth of assortments in a category because most chains in the category carry most of the major brands (i.e., no variation on breadth)
} 
brand in the market, compared to its market share in the the category. Consider a retailer with a total category share of $10 \%$. For brand one they have a $15 \%$ share and consequently a BDI of 150 , whereas for brand two they have a $5 \%$ market share and consequently a BDI of 50. The BDI allows manufacturers to understand whether a retail chain is under-performing or over performing relative to other accounts for the brand. This measure has shown to be particularly useful (Dhar et al. 2001) because it provides a standardized basis for comparing brand performance across geographic or national markets. This is in contrast to other assessments based on store size which are potentially confounded with population density. The control variables that I use are known to have impact on BDI. Lower prices (measured as average brand price) should have a positive impact on brand performance. Similarly, the total number of SKUs of each brand carried by the retail chain, number of stores in that chain carrying the brand, and other promotional activities (display, feature) should positively affect brand performance.

Table A.3 displays the coefficients from the analysis. First, the coefficients on the control variable are directionally consistent and significant. Second, and more importantly the captaincy indicator is positive and significant indicating that captaincy does play a significant role in the performance of the brand. The analysis was relatively unchanged when $\$$ sales was used instead of unit volume in the BDI measure. I also ran an analysis to identify the impact of captaincy on assortment share and average price. Table A.3 also contain the results from this analysis. In general, the results support the idea that category captain arrangements influence assortment share and prices. The summary statistics and reduced form estimates provide strong evidence that category captains influence performance, prices and assortment in the frozen pizza category. However, most of the variation necessary for identification of the captaincy effect comes from cross-sectional variation in captaincy across chains 10 . The lack of variation is not uncommon in inter firm relationships which are generally long term in nature and are sticky. This however creates a problem in separating the captaincy effect from a chain effect (chain-captaincy interaction effect). While I do not possess enough variation to individually separate each chain effect, I illustrate the impact of captaincy effect on the above dependent variables on a case by case basis using two chains which

10 Of the 24 chains that I observe for 2 years, only 4 changes in captaincy were observed 
undergo a change in captaincy.

Of the two chains which undergo a change a captaincy, one switched captains from Firm B to Firm A while the other switched from Firm A to category management by the retailer. Tables A.5 and A.6 show the variation in BDI, assortment shares and prices between the two regimes. First, note that the variation is in line with the above analysis. When chains switch captains, BDI, assortment shares and prices of captains goes up while that of the rival goes down. For e.g., in Table A.6 BDI for Firm A goes up from 75.98 to 87.13 when Firm A becomes a captain while BDI for the rival's firm goes down from 192.77 to 55.40. Similarly BDI for Firm A goes down when it loses captaincy to the retailer.

Overall, the above analysis presents some strong suggestive evidence on the impact of captains on category performance. However this analysis is inadequate as it cannot be used to compute profits for the different actors or calculate consumer welfare. Further, while I observe the assortment, market shares and prices for chains when they had a category captain, I do not observe what the assortment, market shares and prices would have been if there had been no category captain. To isolate the impact of category captaincy on assortments and prices, I construct a structural model. 


\section{Chapter 4}

\section{Model}

My structural empirical model consists of three main components: i) a demand model that captures consumer preferences for products, ii) a pricing model that captures the interactions between manufacturers and suppliers, and iii) an assortment selection model that captures the tradeoffs between the increased revenues from adding a product to the assortment and the increased costs of a bigger assortment.

The intuition of my model setup is as follows. Assortment selection depends upon demand factors (what will a consumer do if a product of his choice is not available), the competitive landscape (the next best option) and costs (inventory, stocking and replenishment costs). These in turn depend on substitution patterns between products, vertical interactions between manufacturers and retailers and horizontal interactions between manufacturers. When a product is not available on the shelf, a consumer is likely to either buy another product within the same category or go to another retail store to buy the same product. The retailer's incentive while choosing assortments is to minimize the lost sales by choosing products which are easily substitutable. In addition, retailers gain due to upstream competition between manufacturers when the competing products are closer in product space. On the other hand, manufacturers prefer assortments where they are differentiated from one another. These differences in motivations lead to different assortments and prices under category captain arrangements and without. My model is structured to capture the differences in incentives between the manufacturers and retailers to recover the underlying cost transactions.

The timing of decisions is as follows. In stage 1 category managers (either category 
captains or retailers) pick the assortment to be offered, in stage $\mathbf{2}$ manufacturers set wholesale prices, in stage 3 retailers set retail prices, and finally, consumers make purchases and consume the good. I describe each of the stages below, starting backwards with consumer demand.

\subsubsection{Consumer Demand}

I model demand using a discrete choice random coefficient model of consumer utility as in BLP. The BLP specification accommodates differences in consumer preferences for products in a category while simultaneously controlling for endogeneity of prices. The demand estimation is at the chain county leve 1 . A product in this context is defined as a stock-keeping unit (SKU) in the premium frozen pizza category. A set $\Omega_{c r t} \subset \Theta_{\text {crt }}$ of products is available to every chain $c$ in region ${ }^{2} \quad r$ at time $t$, where $\Theta_{c r t}$ is the superset of all products that are available in time period $t$. Each individual consumer $i$ chooses a product $j_{c r t} \in \Omega_{\text {crt }}$ in every time period $t$ or chooses the outside option. Every product offered in time period $t$ consists of attributes $\left(X_{j c r t}, \xi_{j c r t}, p_{j c r t}\right) . X_{j c r t}$ includes i) product characteristics that do not vary over time like package size, toppings, crust, etc., ii) brand fixed effects and, iii) seasonal effects. $\xi_{j c r t}$ are product characteristics that are observable to the consumer but unobservable to the econometrician, e.g., shelf space and $p_{j c r t}$ denotes the price for product $j$ at time $t$ for chain $c$ in region $r$. For ease of notation, I drop the time $t$ and region $r$ subscripts in the following equations. The individual utility specification is as follows:

$$
U_{i j c}=\left(Y_{i}-p_{j c}\right) \alpha_{i}+X_{j c} \beta_{i}+\xi_{j c}+\epsilon_{i j c}
$$

where $i$ is the individual, $j$ is the product and $c$ is the retail chain. In this specification, $Y_{i}$ is the income of the individual and $\alpha_{i}$ is the marginal utility of income. $\beta_{i}$ captures the preference for observed product attributes including taste for brands. $\epsilon_{i j c}$ captures consumer $i$ 's idiosyncratic utility for each product $j$ in chain $c$ and follows an IID extreme value Type 2 distribution. Consumer preferences are assumed to be distributed normally across the population and are given by:

\footnotetext{
1 In line with other work that examines chain/brand level effects (Chen et al. 2008), I restrict demand to the chain level and not the store level

2 I use the terms region and geographic markets interchangeably in this paper
} 


$$
\begin{aligned}
& \alpha_{i} \sim N\left(\alpha, \sigma_{\alpha}^{2}\right) \\
& \beta_{i} \sim N\left(\beta, \Sigma_{\beta}\right)
\end{aligned}
$$

where $\alpha$ and $\beta$ capture the average marginal utility of income and average preference for observed attributes respectively, while $\sigma_{\alpha}$ and $\Sigma_{\beta}$ capture the variation in the marginal utility of income and the preference for observed attributes in the population, respectively. The utility for the outside option is given by:

$$
U_{0 c}=Y_{i} \alpha_{i}+\epsilon_{i 0 t}
$$

Following standard practice, I further assume that the consumer's inherent preference for the outside option is equal to zero.

Rewriting the utility specification as mean effects and terms that vary by individual gives the following equation

$$
U_{i j c}=\delta_{j c}+\nu_{i j c} X_{j c}-\lambda_{i j c} p_{j c}+\epsilon_{i j c}
$$

where $\delta_{j c}$ is equal to $p_{j c} \alpha+X_{j c} \beta+\xi_{j c}$ and is known as the linear part of the utility function (Nevo 2000b). $\lambda_{i j c}$ and $\nu_{i j c}$ denote the individual's preference for marginal income and observed attributes respectively and are represented as variations from the mean. The expression $\nu_{i j c} X_{j c}-p_{j c}+\epsilon_{i j c} \equiv \mu_{i j c}$ is often referred to as the non-linear part of the utility (Nevo 2000b). Consumer heterogeneity is represented as:

$$
\begin{array}{r}
\alpha_{i}=\alpha+\sigma_{\alpha} \lambda_{i} \\
\beta_{i}=\beta+\Sigma_{\beta} \nu_{i} \\
\nu_{i}, \lambda_{i} \sim N(0,1)
\end{array}
$$

The model predicted share of product $j \in \Omega_{c}$ is given by:

$$
s_{j c}(x, p, \delta, \nu, \lambda)=\int \frac{\exp \left[\delta_{j c}+\mu_{i j c}\left(x_{j c}, p_{j c}, \nu_{i}, \lambda_{i}\right)\right]}{1+\sum_{m \in \Omega_{c}} \exp \left[\delta_{m c}+\mu_{i m c}\left(x_{m c}, p_{m c}, \nu_{i}, \lambda_{i}\right)\right]} d F_{\nu, \lambda}\left(\nu_{i}, \lambda_{i}\right)
$$

where $F_{\nu, \lambda}\left(\nu_{i}, \lambda_{i}\right)$ is the joint distribution of $\nu_{i}, \lambda_{i}$. 


\section{Supply}

Product assortment decisions primarily vary along three dimensions. At the highest level of aggregation, manufacturers decide what products to introduce and where. These products are then available to all the retail chains in a region. Second, retail chains decide what assortments to carry at their chain; these products are available to all stores within that chain. Finally, stores within a chain can choose the products to stock from this superset depending on the demand they face. Deciding which dimension to focus on depends on the research question. For example, the focus of Draganska et al. (2008) is to explain differences in product line introductions by manufacturers (a manufacturer level decision). Similarly, the goal of Misra (2008) is to examine variation in store assortments (a store level decision). In this research, the objective is to understand differences in assortment and prices across different category captain arrangements. I therefore choose the chain as my level of analysis. The reason behind this choice is that category captain arrangements are contracts between the manufacturer and the retailer for the entire chain. My phenomenon of interest is thus most sensibly viewed as a chain level phenomenon.

In particular, I assume that in each time period the category manager of a retail chain chooses a subset of products for the region from a predetermined superset of products that are known and available to all chains in that region. The assumption on the set of products available for selection controls for i) variation in assortments within stores in a particular chain and ii) variation in product offerings by manufacturers across different regions, thereby allowing me to focus on variation in assortments due to differences in category management. I further assume that this superset of products is the union of all products stocked across all the chains in this region. The timeline for the 3-stage game played by the manufacturers and retailers in each quarter, is:

1. Category Managers (either category captain or retailer) observe realizations of shocks to fixed costs that are unobserved by the econometrician; they then simultaneously choose the assortment to carry and incur a fixed cost for each product carried.

2. For each product carried in the assortment, manufacturers observe realizations of demand and marginal cost shocks that are unobserved by the econometrican; they 
choose wholesale prices simultaneously.

3. After the wholesale prices are set, retailers choose final retail prices for all products in the assortment simultaneously.

The reason for modeling assortments and prices sequentially instead of simultaneously requires some justification. Assortment decision are stickier than pricing decisions; the former are made once a quarter as opposed to pricing decisions which are made more frequently. Therefore assuming that assortment decisions are made before demand shocks are realized is justified.

\section{Assortment selection - Category Captain}

In situations where category captaincy exists, retailers delegate assortment decisions to category captains. This can lead to obvious opportunistic behavior by the category captain, i.e., when the category captain is maximizing his profits, then the trivial equilibrium solution would be to stock only his own products and none belonging to his rivals. To avoid this trivial solution, I impose the constraint that, in expectation, the retailer must make at least as much profits within a category captain arrangement as he did prior to the category captain arrangement. In addition to this constraint, the category captain must consider two additional factors when deciding on products to include in an assortment: i) adding a product to an assortment incurs a fixed cost and ii) introducing products with similar characteristics will reduce markups due to more intensive cross-substitution. These two factors will push the category captain towards introducing products that are differentiated from one another. The constraint imposed by the retailer prevents the category captain from dropping a rival's product if he does not have a close substitute for it.

The fixed costs that the category captain incurs to include a product in the assortment, may include inventory management costs that are necessary to ensure that the product configuration is in stock, administrative and marketing costs. Formally, the fixed costs of adding a product $j$ are given by:

$$
F_{j c}=F^{c}\left(X_{c}, \mu\right)+\nu_{j c}, E\left[\nu_{j c} \mid I_{c}\right]=0
$$


where the specification consists of a mean fixed cost $F^{c}$ and a mean-zero error term. $F^{c}$ varies with $X_{c}$ which are chain and store level indicators. The specification allows for the fixed costs to vary by chain, region and time. The mean fixed cost is identical for all products in an assortment belonging to a chain. This is a reasonable assumption to make in this category, as most products are of the same package size. $I_{c}$ is the information set based on which assortment decisions are made. This consists of the number of products in the superset and the size of the chain (number of stores).

The category captain chooses an assortment $\Omega_{c} \subset \Theta_{c}$ after observing shocks $\nu_{j c}$ based on the following value function:

$$
V_{c}\left(\Omega_{c} \mid \Xi\right)=E_{\xi, \epsilon \in \Xi}^{C C}\left[\pi_{c}\left(p^{r}, p^{w}, \Omega_{c} \mid \xi, \epsilon, X, \theta\right)\right]-\sum_{j_{c} \in \Omega_{c}} F_{j c}
$$

subject to the constraint that

$$
E_{\xi, \epsilon \in \Xi}^{r}\left[\pi_{c}\left(p^{r}, p^{w}, \Omega_{c} \mid \xi, \epsilon, X, \theta\right)\right] \geq \bar{\pi}^{r}
$$

where $\Xi$ is the distribution of demand shocks $\xi$ and cost shocks $\epsilon$.

$E_{\xi, \epsilon \in \Xi}^{C C}\left[\pi_{c}\left(p^{r}, p^{w}, \Omega_{c} \mid \xi, \epsilon, X, \theta\right)\right]$ is the expected profit to the manufacturer from choosing assortment $\Omega_{c}, E_{\xi, \epsilon \in \Xi}^{r}[\cdot]$ is the expected profit that the retailer makes from the current assortment and $\bar{\pi}^{r}$ is the average profit the retailer makes before the category captain arrangement.

The constraint imposed by the retailer is "soft" in that it allows the category captain to add or drop any product to the assortment, but at a cost. The form of the soft constraint is similar to that used in Snider (2009), Doraszelski and Besanko (2004) and Doraszelski et. al. (2008). The cost of the assortment is :

$$
V C\left(\Omega_{c}\right)=\left(\frac{\tau}{1+\nu}\right)\left(\frac{\bar{\pi}^{r}}{E_{\xi, \epsilon \in \Xi}^{r}[\cdot]_{\Omega_{c}}}\right)^{\nu}
$$

where $E_{\xi, \epsilon \in \Xi}^{r}[\cdot]_{\Omega_{c}}$ is the expected profit to the retailer when the category captain chooses assortment $\Omega_{c}$, and $\nu \geq 0$ measures the hardness of the capacity constraints. As $\nu \rightarrow \infty,\left(\frac{\bar{\pi}^{r}}{E_{\xi, \epsilon \in \Xi}^{r,}[]_{\Omega_{c}}}\right) \rightarrow 0$ if $E_{\xi, \epsilon \in \Xi}^{r}[\cdot]_{\Omega_{c}}>\bar{\pi}^{r}$ or is equal to $\infty$ if $E_{\xi, \epsilon \in \Xi}^{r}[\cdot]_{\Omega_{c}}<\bar{\pi}^{r}$. Finally $\tau$ captures the effect of this constraint. 
Rewriting the category captain's value function using the "soft" constraints gives,

$$
V_{c}\left(\Omega_{c} \mid \Xi\right)=E_{\xi, \epsilon \in \Xi}^{C C}\left[\pi_{c}\left(p^{r}, p^{w}, \Omega_{c} \mid \xi, \epsilon, X, \theta\right)\right]-\sum_{j_{c} \in \Omega_{c}} F_{j c}-V C\left(\Omega_{c}\right)
$$

category captains offer the assortment that maximizes their value function, i.e.,

$$
\left.V_{c}\left(\Omega_{c} \mid \Xi\right)>V_{c}\left(\Omega_{c}^{\prime} \mid \Xi\right)\right) \forall \Omega_{t}^{\prime} \subset \Theta_{t}
$$

I use the above equation to obtain moment inequalities that are used in my estimation.

\section{Assortment Selection - Retailer}

In retail chains where no category captain arrangements exist, retailers make the assortment decision. Retailers face fixed costs when including a product. The retailer therefore will introduce products until the expected profit from the expanding assortment is less than the fixed cost of product addition. Unlike the category captain situation, introducing products with similar characteristics does not necessarily reduce markups for the retailer. The difference arises because while the category captain is choosing products to differentiate his products from his rival manufacturers, the retailer is choosing assortments to prevent substitution to the outside good. Further, retailers also act as local monopolies and benefit from competition between manufacturers.

Similar to the category captain, the retailer incurs a fixed cost to include a product in the assortment, given by

$$
F_{j c}=F^{c}\left(X_{c}, \mu\right)+\nu_{j c}, E\left[\nu_{j c} \mid I_{c}\right]=0
$$

The specification implies that the fixed cost of adding a product $j$ is given by a mean $F^{c}$ and a mean-zero error term, and it allows the fixed costs to vary by chain, region and time. The mean fixed cost is identical for all products in this assortment.

The retailer chooses an assortment $\Omega_{c} \subset \Theta_{c}$ based on the following value function

$$
V_{c}\left(\Omega_{c} \mid \Xi\right)=E_{\xi, \epsilon \in \Xi}^{r}\left[\pi_{c}\left(p^{r}, p^{w}, \Omega_{c} \mid \xi, \epsilon, X, \theta\right)\right]-\sum_{j_{c} \in \Omega_{c}} F_{j c}
$$

Again, $\Xi$ is the distribution of demand shocks $\xi$ and cost shocks $\epsilon$. 
$E_{\xi, \epsilon \in \Xi}\left[\pi_{c}\left(p^{r}, p^{w}, \Omega_{c} \mid \xi, \epsilon, X, \theta\right)\right]$ is the expected profit to the retailer from choosing assortment $\Omega_{c}$.

The optimal assortment decision for the retailer is obtained by maximizing the value function, i.e.,

$$
\left.V_{c}\left(\Omega_{c} \mid \Xi\right)>V_{c}\left(\Omega_{c}^{\prime} \mid \Xi\right)\right) \forall \Omega_{t}^{\prime} \subset \Theta_{t}
$$

Similar to the category captain scenario, I use the above equation to obtain moment inequalities that are used in our estimation framework.

Once the assortment decision is made, manufacturers and retailers observe demand and cost shocks, after which wholesale and retail prices are chosen. I turn to these issues below.

\section{Manufacturer Pricing}

Manufacturers choose prices to maximize profits from their portfolio of products. The profit function for each manufacturer $w$ in chain $c$ in region $r$ at time $t$ is given by:

$$
\pi_{c}^{w}\left(p_{t}^{w}\right)=\sum_{j \in \Phi_{w c}}\left[p_{j c}^{w}-c_{j c}^{w}\right] s_{j c}\left(p_{j c}^{r}\left(p_{j c}^{w}\right)\right)-C_{c}^{w}
$$

$\Phi_{w c} \subset \Omega_{c}$ is the set of all products that manufacturer $w$ sells to retailer $c, c_{j c}^{w}$ is the marginal cost for manufacturer $w$ to produce product $j, p_{j c}^{r}$ is the retail price when manufacturer charges wholesale price $p_{j c}^{w}$, and $C_{c}^{w}$ is the fixed cost incurred by the manufacturer to serve a particular chain ${ }^{3}$. The FOCs for the manufacturer are given by:

$$
p_{c}^{w}-c_{c}^{w}=-\left[T_{w} \times \Delta_{c}^{w}\right]^{-1} s_{c}^{r}(p)
$$

$T_{w}(i, j)=1$ if manufacturer $w$ owns both product $i$ and $j$, and is zero otherwise. $\Delta_{c}^{w}$ is the demand response to wholesale price as in Villas-Boas (2006) and is given by $\Delta_{c}^{w}(j, k)=\frac{\partial s_{j c}\left(p_{j c}^{r}\right)}{\partial p_{k c}^{w}}$.

\footnotetext{
3 In a DSD channel, most of these fixed costs are the costs of distribution, e.g., purchasing new trucks etc,. In addition to these costs, the category captain manufacturer incurs an extra cost of managing the assortment
} 


\section{Retail pricing}

Retailers choose prices to maximize category profits with products competing with each other in a Bertrand- Nash fashion. Retailer profits are given by

$$
\pi_{c}\left(p^{r}, p^{w} \mid \xi, \epsilon, X, \theta\right)=\sum_{j_{c} \in \Omega_{c}}\left[p_{j c}^{r}-p_{j c}^{w}-c_{j c}^{r}\right] s_{j c}\left(p_{j c}^{r}\right)-C_{c}^{r}
$$

where $p_{j c}^{r}$ is the price charged by retailer $c$ for product $j, p_{j c}^{w}$ is the wholesale price charged by the manufacturer to the retail chain $r$ for product $j$ as a function of all prices in the time period, and $C_{c}^{r}$ includes all retail fixed costs that do not change with time, such as electricity and marketing costs. I assume, that retailers set price to maximize profits, i.e.,

$$
p^{r *}=\operatorname{argmax} \pi_{c}\left(p^{r}, p^{w}\right)
$$

where $p^{r *}$ is a vector of optimal prices charged by the retailer. The first order conditions (FOCs) are:

$$
s_{k c}\left(p_{k c}^{r}\right)+\sum_{j_{c} \in \Omega_{c}}\left[p_{j c}^{r}-p_{j c}^{w}-c_{j c}^{r}\right] \frac{\partial s_{j c}\left(p_{j c}^{r}\right)}{\partial p_{j c}^{r}}=0
$$

Written in matrix form, the price-cost margins are

$$
\left(\begin{array}{c}
\vdots \\
P_{t}^{r} \\
\vdots
\end{array}\right)-\left(\begin{array}{c}
\vdots \\
P_{t}^{w} \\
\vdots
\end{array}\right)-\left(\begin{array}{c}
\vdots \\
M c_{t}^{r} \\
\vdots
\end{array}\right)=-\left(\begin{array}{ccc}
\ddots & \vdots & \ddots \\
\ldots & T_{r} \times \Delta_{t}^{r} & \ldots \\
\ddots & \vdots & \ddots
\end{array}\right)^{-1}\left(\begin{array}{c}
\vdots \\
S_{t}^{r} \\
\vdots
\end{array}\right)
$$

where $P_{t}^{r}$ is a vector of all retail prices at time $t$ while $P_{t}^{w}$ is the vector of all wholesale prices charged by manufacturers to retailers. $M c_{t}^{r}$ is the vector of marginal costs for products at time $t . T_{r}$ is a matrix indicating the ownership structure, i.e., $T_{r}(i, j)=1$ if retailer maximizes profits for product $i, j$ and zero otherwise. $\Delta_{t}^{r}$ is a matrix of own and cross-price elasticities and is given by $\Delta_{t}^{r}(j, k)=\frac{\partial s_{j t}\left(p_{j t}^{r}\right)}{\partial p_{k t}^{r}}$, and $S_{t}^{r}$ is a vector of market shares for all products. Rewriting the above equation we get:

$$
P_{t}^{r}-P_{t}^{w}-M c_{t}^{r}=-\left[T_{r} \times \Delta_{t}^{r}\right]^{-1} S_{t}^{r}
$$




\section{Chapter 5}

\section{Estimation}

The parameters to be estimated are the demand parameters $\theta^{d}=\left(\alpha_{i}, \beta_{i}\right)$, the marginal cost parameters $\gamma$ and the fixed cost parameters $\mu, \tau$. The estimation strategy consists of i) estimating the demand and marginal cost parameters $\theta^{d}, \gamma$ to obtain estimates of profits conditional on observed assortment choices, and ii) estimating bounds on the fixed cost parameters using the estimates from the previous step. The following sections describe the estimation strategy in detail.

\section{First stage estimation-demand and marginal cost estimates}

Following recent literature (Berto Villas-Boas |2006; Chen et al.|2008), I estimate demand and supply sequentially using a generalized method of moments (GMM) estimation procedure. On the demand side I use the BLP (1995) procedure to obtain the means and standard deviations of the coefficients of price, brand and the other variables in the random coefficients logit model (equation 4.1). Briefly, I first solve for the mean utility numerically using a contraction mapping. This yields a linear equation relating mean utility to the product preference dummies, prices, and other exogenous variables. As pointed out in the literature, the prices set by firms are likely to depend on unobserved product attributes $\left(\xi_{j t}\right.$ in equation 4.1$)$, which means that price is effectively an endogenous variable, and I need to instrument for it to obtain consistent estimates. The standard BLP (1995) procedure involves an instrumental variables (IV) regression, with the residuals from the regression used as the residuals in a GMM estimation, described 
below.

On the supply side, the specification of a Bertrand-Nash pricing game by the retailer leads to a certain implied price-cost margin, which can be calculated once I have estimates of the demand-side parameters in place. I combine this calculation of the price-cost margin with the assumption of a Stackelberg game between the retailer and manufacturers to back out wholesale prices and manufacturer costs. I assume that the retailer incurs no additional marginal costs beyond the wholesale price paid to the manufacturen $\square^{1}$. I then regress these costs on a set of cost characteristics. Formally, I assume that the marginal cost for a product in region $r$ at time $t$ is:

$$
c_{j t}^{w}=\gamma X_{j}^{c}+\phi_{j t}
$$

where $X_{j}^{c}$ is a vector of cost characteristics, $\gamma$ is the vector of coefficients that affect costs and $\phi_{j t}$ is the portion of costs unobserved by the econometrician. The cost equation captures the costs of transportation, delivery and offering different product attributes. Denoting the price-cost margin as $P C M_{j t}$, I obtain the estimated pricing equation as:

$$
p_{j t}^{w}-P C M_{j t}=\gamma X_{j}^{c}+\phi_{j t}
$$

I assume a constant elasticity of marginal cost for every attribute. While restrictive, this is a justifiable cost function to use, given our lack of information on issues such as economies of scale.

\section{Fixed Cost estimation}

To estimate fixed costs for including a product in an assortment, I use the method of moments inequalities estimator developed in Pakes et al. (2006). This method uses a "revealed preference" approach to recover the parameter values. In other words, I use the assumption that profits from the observed assortment are greater than the profits from alternative assortments that were not offered. Notice that these are the necessary conditions for a Nash equilibrium in this context. For example, consider the case of including a product to the assortment. If the product was added to the assortment,

\footnotetext{
1 This assumption is particularly reasonable in our context given the DSD nature of the channel. Recall from our description of the industry earlier that retailers incur only electricity costs. These costs are fixed costs which do not vary by the number of products sold and drop out of the FOC equation
} 
then it must have been the case that the fixed cost of adding the product was less than the profits from adding the product. Similarly, if the product was not added, then it must have been the case that the profits from the assortment would have been lower. These necessary conditions allow me to construct a inequalities estimator (Pakes et al. 2006) that I use to estimate the fixed costs.

I derive inequalities for every chain's assortment choice in a particular region at a particular time period. The objective function varies depending on whether a category captain arrangement exists or not. The first inequality is obtained by adding a product to the assortment. This generates a lower bound for the product. Similarly, the upper bound is generated by dropping the product from the assortment.

\section{Inequalities estimator}

Recall that the category captain chooses assortment $\Omega_{c} \subset \Theta_{c}$ based on the following value function:

$$
V_{c}\left(\Omega_{c} \mid \Xi\right)=E_{\xi, \epsilon \in \Xi}^{C C}\left[\pi_{c}\left(p^{r}, p^{w}, \Omega_{c} \mid \xi, \epsilon, X, \theta\right)\right]-\sum_{j_{c} \in \Omega_{c}} C\left(X_{c}, \mu\right)
$$

$E_{\xi, \epsilon \in \Xi}^{r}[\cdot]_{\Omega_{c}}$ is the expected profit to the retailer when category captain chooses assortment $\Omega_{c}$ and $C\left(X_{c}, \mu\right) \equiv F_{j c}+V C\left(\Omega_{c}\right)$ is the fixed cost of adding a product to the assortment.

To specify the inequalities estimator, I predict the expected profits for both the observed and alternate assortments. First, I use the demand and marginal cost estimates to predict the profits for an assortment in each chain in a region in a particular time period, i.e.,

$$
\pi_{j t}^{\hat{C} C}\left(\Omega_{c r t} \mid \theta, \gamma, \xi_{j t}, \phi_{j t}\right) \equiv \sum_{\Omega_{c r t}}\left(p_{j t}^{C C}-c_{j t}^{\hat{w}}\right) \hat{s_{j}} M
$$

where [.] represent estimated values. The expected profit is obtained over the distribution of demand shocks $\xi$ and cost shocks $\epsilon$. To do this, I bootstrap 100 times over the predicted values of $\hat{\xi}, \hat{\gamma}$ and recalculate the new prices and market shares. The expected profit is the average over these bootstraps. 
To generate the moment inequality, consider the case where a product is added to the assortment. According to our earlier discussion, the expected value from the current assortment should be greater than the expected value from any other assortment that can be formed by adding any product from the superset. This implies

$$
E\left[V_{c}\left(\Omega_{c} \mid \Xi\right) \mid I_{c}\right] \geq E\left[V_{c}\left(\Omega_{c+1} \mid \Xi\right) \mid I_{c}\right]
$$

where $V_{c}\left(\Omega_{c+1} \mid \Xi\right)$ is the value function obtained from adding a product from assortment $\Omega_{c}$ in chain $c$. The expectation is taken conditional on $I_{c}$, the chain information set at the time when the category captain makes his choice. This generates the following inequality:

$$
\begin{gathered}
E\left[\triangle V_{c}(\cdot \mid \Xi) \mid I_{c}\right]= \\
E\left\{\triangle \pi^{\hat{C} C}\left(\Omega_{c} \mid \theta, \gamma, \xi_{j t}, \phi_{j t}\right)-\triangle C\left(X_{c}, C C\right)+\triangle \nu_{c} \mid I_{c}\right\} \geq 0
\end{gathered}
$$

The difference function $\triangle C\left(X_{c}, C C\right) \equiv F_{c r t}+V C\left(\Omega_{c}\right)-V C\left(\Omega_{c}+1\right)$ and similarly for $\triangle \pi \hat{C} C\left(\Omega_{c} \mid \theta, \gamma, \xi_{j t}, \phi_{j t}\right)$. To obtain the expectation, I add every product that is not in the assortment $\Omega_{c}$ but belongs to the superset of products available to the chain $\Theta_{c}$ to the current assortment and recompute the profits from the new assortment $\Omega_{c+1}$. The upper bound is obtained in a similar way by dropping every product from the assortment one at a time and recomputing expected profits from the new assortment $\Omega_{c-1}$.

The above equation generates one moment. Doing so for all the chains and regions generates 142 moments. Applying a similar methodology to "dropping" a product from the assortment generates an additional 142 moments. Stacking the $1 \ldots J$ moments together gives us the following equation for estimation:

$$
P_{J} m(z, \theta)=\frac{1}{J} \sum_{j} E\left[\triangle V_{c}(\cdot \mid \Xi) \mid I_{c}\right]_{j} \geq 0
$$

The identified set of parameter values is the set of parameters that satisfy the implied system of inequalities and is

$$
\Theta_{j}=\operatorname{argmin}_{\theta \in \Theta}\left\|\left(P_{J} m(z, \theta)\right)_{-}\right\|
$$


where $(\cdot)_{-}=\min \{\cdot, 0\}$. If there are no feasible parameters I use a method of moments methodology, minimizing the Euclidean distance by which the inequalities are violated.

\section{Instruments}

Recall that the term $\xi$ in equation 1 represents unobserved demand shocks. It is highly likely that these time-varying shocks are correlated with the chosen prices, thus creating a potential endogeneity bias. I instrument for the price of a product, to control for this endogeneity. Following Hausman (1996) and Nevo (2001) I use prices of the product in other regions as instruments. The assumption I make here is that after controlling for brand-specific means and demographics, region specific shocks are independent across regions (but are allowed to be correlated within regions). The prices of product $j$ in two regions will be correlated due to the common marginal cost, but due to the independence assumption will be uncorrelated with market specific demand shocks. Specifically, for the price of a given product $j$ in store $r$ at time $t$, I use the average price across other regions, for that product for that time.

\section{Identification}

I now present an informal argument for identification of the estimation parameters. The variation in prices and product attributes identify the demand parameters. The marginal cost parameters are identified from the assumptions on the pricing game combined with the demand parameters. Finally, the timing of the assortment game allows me to identify the fixed cost parameters. In particular, the assumption that assortment decisions are made on an expectation of demand and cost shocks is critical to my identification strategy. Absent this assumption, I have to account for selection effects that arise. The various fixed cost parameters are identified from the variation in category captain arrangements across chains. In particular, conditional on the demand, differences in assortments across chains within the same market can be explained by variation in captaincy arrangements. 


\section{Chapter 6}

\section{Results}

\section{Demand Results}

I run the demand model separately for the seven geographic markets, both for computational ease and to allow preferences to vary flexibly across markets. I report the results from the Baltimore geographic market. Table A.7 reports consumer demand results for three different specifications: a simple logit specification, which involves an OLS regression with the difference between $\log$ (share) of each of the inside goods and the

outside good (i.e., $\ln \left(\frac{s_{j}}{s_{0}}\right)$ ) as the dependent variable, with no instruments for price and no control for unobserved heterogeneity; a logit estimation with instruments for price but no control for unobserved heterogeneity (denoted logit+IV); and a random coefficients logit model with instruments for price and controls for unobserved heterogeneity (denoted RC logit+IV).

I find that accounting for price endogeneity makes a significant difference - the mean price sensitivity under OLS is -0.31 and under logit + IV estimation is -0.35 . The downward bias towards zero is evidence for price endogeneity. The discussion that follows focuses on the random coefficient logit estimates. Turning to the estimates of brand constants, observe that Frechetta is the strongest brand followed by California Pizza Kitchen. This is consistent with the distribution of market shares and prices. The mean price coefficient is significantly negative $(-2.38)$. The weight of the product influences demand positively - intuitively this implies that customers in general prefer more toppings to less. 
I repeat the demand analysis for the remaining six geographic markets. As expected, there is some variation in results across the regions but the results are broadly consistent. (For instance, the average price varies from a minimum value of -0.17 to a maximum of -4.07$.

\section{Cost Results}

Table A.14 shows the results for the cost regression from equation 12. First, note that the cost estimates seem to satisfy face validity constraints; pizzas with more toppings are more expensive to make. Second, there is a fair amount of heterogeneity across firms in their ability to produce at low cost. In general, my estimates imply an average cost of $\$ 3.49$ for producing a unit of pizza. The wholesale and retail price margins implied by my estimation are in the range of $\$ 1.10-\$ 2.00$. Conversations with managers confirmed the validity of my margin estimates.

Table A.15 describes the results from the inequalities estimation. I employ a specification for the cost of adding an SKU to the assortment that contains the following variables: a constant, average store siz€ $\Theta^{1}$, an indicator for category captain arrangement and the penalty function 2 . The estimates of the fixed cost was a singleton for all specifications, i.e. I obtain a point estimate instead of a bounds estimate. As noted in Pakes (2007), this does not imply that the specification must be rejected. The probability that all inequalities will be satisfied can be made arbitrarily small by increasing the number of inequality restrictions. I report the conservative $95 \%$ confidence intervals derived in Pakes et al. (2006).

The coefficient on the assortment size is positive, indicating that stores with bigger assortments face higher costs of adding products to the assortment. This is reasonable given that marketing and advertising costs are bound to go up with a bigger assortment mix. The negative coefficient on the category captain dummy implies that chains with category captain arrangements face lower costs per SKU than chains without. Evidently

\footnotetext{
1 I use average assortment size as a proxy for store size problem. In general, bigger stores carry bigger assortments while smaller stores carry smaller assortments. This measure is used to capture this fact

2 Recall that the penalty function applies only in instances where category captain arrangements are present and is given by $\left(\frac{\tau}{1+\nu}\right)\left(\frac{\bar{\pi}^{r}}{E_{\xi, \epsilon \in \Xi}^{r}[]_{\Omega_{c}}}\right)^{\nu}$. The parameter $\nu$ is a scaling parameter and is not identified. However, a higher value of $\nu$ implies a harder constraint. The results reported are for $\nu=10$. Robustness checks involving $\nu \in(2,12)$ give similar results
} 
category captains are more efficient in managing category assortments. Finally, the coefficient on the variable capturing the magnitude of the penalty function incurred by the category captain is positive indicating that category captains incur a positive cost for not meeting the retailer's constraint.

The estimates suggest that the average fixed cost of adding a SKU to frozen pizza assortment in a chain with average assortment size of 45 is around $\$ 3,200$ per chain per quarter. Note that my fixed cost estimates refer to the economic costs of adding a product to the assortment and are different from standard accounting costs. The fixed costs estimate for the same chain under a category captain arrangement is around $\$ 800^{3}$ per chain per quarter which is considerably lower than $\$ 3200$. The finding that fixed costs under category captain arrangements are lower than fixed costs under retail category management implies that manufacturers are more efficient in choosing assortments than retailers. This finding is in line with arguments that suggest that manufacturers possess a lot of expertise, given their experiences with product developments in the category. Manufacturers can thus leverage these capabilities to incur lower costs.

\footnotetext{
3 Interpreting the fixed cost estimates for adding an SKU to the assortment under category captain arrangements is slightly difficult as it also depends on how close the profits earned by the retailer are to the retailer's profit constraint. The numbers reported are for a marginal product, i.e. a product at which the retailer's constraint is satisfied
} 


\section{Chapter 7}

\section{Counterfactuals}

My goal is to analyze the impact of category captain arrangements on producer and consumer surplus. To conduct this counterfactual, I need to identify the optimal assortment and prices that would be selected in the alternate arrangement. Since my estimation does not specify an assortment selection procedure, I have to enumerate all possible assortment combinations to arrive at the optimal assortment. This is computationally intensive, e.g., computing the optimal assortment from a superset of 50 products requires me to enumerate $2^{50}-1$ combinations. As such, I restrict myself to a subset of 15 products. I proportionally sample these 15 products from the superset of products available to the chain in that region and observe how assortment selection and prices vary under category captain and non category captain arrangements. Computationally, the counterfactual choices are computed in the following steps:

1. Identify an assortment combination

(a) Simulate demand and cost shocks for the assortment combination

(b) Predict demand and cost residuals for the chosen assortment

(c) Compute optimal retail and wholesale prices

(d) Compute the profit function given costs and the optimal prices

(e) Repeat the process for 100 realizations of demand and cost shocks to compute average profits for the given assortment combination 
2. Do this for the next assortment combination till all the various assortment combinations are exhausted

3. The optimal assortment is the one that generates the highest profits.

Again, for the sake of confidentiality I refer to the two manufacturers as Firm A and Firm B. I conduct two counterfactuals with data from a chain in Baltimore; in the first scenario the retailer manages the category, and in the second scenario Firm A manages the category. The chain I examine does not have a captaincy arrangement. So the base case scenario is one with the retailer managing the category. The results from the counterfactuals detailed in Table A.16 present some interesting patterns.

Assortment size and composition: First, the size of the assortments goes up under captaincy. This is due to a combination of two factors - the lower costs of managing assortment under captaincy and the constraint imposed by the retailer. In the counterfactual context that I examine, Firm B has 5 products and Firm A has 10 products. Despite having fewer products, Firm B's products account for $65 \%$ of the demand. Absent the retailer's constraint, captaincy would have lead to the dropping of all of rival's SKUs. Instead, the captain ends up carrying 4 of Firm B's SKUs. The change in the composition of the assortment is also evident in the shift to category captaincy. In what we dubbed as the market-coverage and substitution effect, not only does the captain add more products to the assortment, he also drops the rival's SKU and replaces it with his own. Because of the retailer's constraint, he is forced to compensate one of the rival's SKU's with 5 of his own. Given that the rival's SKUs are more popular, this is not surprising. The trends in assortment size and composition that I find in my counterfactual seem to fit with observed patterns in the data and industry notions of "ties" belonging to the category captain. The Conwood vs UST case is an extreme example of this bias in assortment selection that the Supreme Court held to be an illegal abuse of power. My counterfactual analysis highlights the important role of retailer in "policing" the process.

Prices and Market Share: On an average, retail prices goes up and market shares go down, albeit by a very small amount. The distribution of prices and market shares is in line with observed behavior - prices of the captain's products go down while those of the rival go up. Likewise, market shares of rival products go down 
while those of the captain go up. However, most of the changes in prices and market shares is explained by the addition/deletion of SKUs, similar to what was observed in our descriptive data. These findings present some face validity to our counterfactuals. Translating these numbers to net revenues, retailer's net revenue goes up by $11 \%$ under captaincy arrangements while those of the rival manufacturer goes down by $16 \%$. Firm A obviously gains under captaincy with net revenues going up by $67 \%$.

Profits and Consumer Welfare: Moving on to producer surplus, channel profit: ${ }^{1}$ go up under category captaincy. On average, channel profits are $\$ 57,535$ more under category captain arrangements. This gain is largely due to the reduction in fixed costs. While the channel seems to benefit, category captain arrangements are not without their "losers". Firm B faces substantially lower profits (around the tune of $\$ 10,000$ ) under category captain arrangements. Finally, consumer surplus 2 goes up under captaincy.

The counterfactual results are informative for a couple of reasons. First, they provide insight into the nature of efficiency gains; specifically my results indicate that category captain arrangements produce two distinct effects, one an efficiency enhancing effect which reduces channel costs and two, an effect that disadvantages rivals by reducing their shelf-space. My counterfactual results show that channel profits increase, despite the fact that rival manufacturers make lower profits under category captain arrangements. This is because the category captain is able to strategically choose products that change the competitive landscape and gain market share for some products. The impact of category captain arrangements is not restricted to transfers between manufacturers and retailers - changes in assortment and pricing affect consumer welfare also. In particular, I find that consumer welfare goes up under captaincy. The effect on consumer welfare is somewhat surprising because it reveals that both the category captain and the retailer are able to transfer some of their gains to consumers. Second, the counterfactuals show how important it is to analyze non-price service elements to gain a fuller picture of these arrangements. Captaincy arrangements see the addition of more SKUs and

1 Defined as the sum of retailer and manufacturer profits

2 Consumer surplus is calculated based on compensating variation (Song 2007) and is given by

$$
C W_{t}=\sum_{i=1}^{n s} \frac{\log \left(\sum_{j=1}^{J} \exp \left(\delta_{j}-\alpha_{i} p_{j}\right)\right)}{\alpha_{i}}
$$


a different assortment composition. Manufacturers can and do alter the competitive landscape by determining which SKUs are available on the shelf. The counterfactuals show that this practice can be surprisingly surplus enhancing for both retailers and consumers. Anti-trust analysis that aims to understand the impact of category captain arrangements must account for the role of non-price elements to fully account for the different incentives. Finally, my counterfactuals highlight the important role of the retailer in preventing the abuse of captaincy arrangements (formally captured in my model through the constraint that he make at least as much profit as in a situation of no captaincy). 


\section{Chapter 8}

\section{Conclusion and Discussion}

In this paper, I examine the impact of category captain arrangements on assortments and prices. Vertical arrangements like category captaincy and slotting fees have always been the subject of anti-trust concern. However, empirical work in this area has been significantly lacking. Given the financial scope and magnitude of the retail industry, minor improvements arising from vertical arrangements can have large impact on manufacturer and retailer profits, and consumer welfare.

My focus on assortments and prices is markedly different from extant literature. I estimate a structural model that explicitly accounts for differences in consumer preferences, the strategic interaction between the manufacturers (horizontal competition) and interaction between manufacturers and retailers (vertical). The demand estimation is based on a random coefficients logit specification and allows me to recover substitution patterns between different products. My supply side estimation backs out marginal costs for each product and the fixed cost of adding a product to an assortment.

I find that category captain arrangements improve channel profits and lead to higher consumer welfare. However, rival manufacturers see reduced profits. Category captaincy yields higher consumer surplus, because of different product introduction incentives. I also find that product differentiation increases under category captaincy. In conclusion, category captaincy in this context appear to be efficiency enhancing according to the benchmarks used by anti-trust authorities. However, rival manufacturers appear to be making lower profits under this arrangement. While a legal recourse may not be available to rivals, there are several options available to rectify the situation. The most 
obvious one would be to become a category captain. However, most manufacturing firms might lack the financial and managerial capability to become one. In the absence of sufficient resources to become the category captain, manufacturing firms can focus their efforts on introducing products that attract a loyal consumer base or improve their marketing efforts at the store level.

Given the absence of empirical work on category captain arrangements, I believe my work is a first step in identifying the impact of captaincy on prices and assortments. Currently, I assume that the category captain controls the entire assortment selection process and incurs the entire costs of managing the assortment. It is reasonable to believe that this assumption will not be true in reality and will vary based on power differences between retailers and manufacturers. A fruitful avenue for future work would be to relax this assumption by incorporating a bargaining framework to account for the differences. A second area of future work might be to incorporate the category captain selection process into the whole system. An explicit model of selection may be required to capture the incentives in this latter case. 


\section{Chapter 9}

\section{References}

Aguirregabiria, V. (2005). Retail stockouts and manufacturer brand competition. Working Paper, January.

Albeniz, V. M. d. and Roels, G. (2007). Competing for shelf space. Working Paper, November.

Anderson, E. T., Fitzimons, G. J., and Simester, D. (2006). Measuring and mitigating the costs of stockouts. Management Science, Vol. 52 (November)(No. 11):1751-1763.

Anupindi, R., Dada, M., and Gupta, S. (1998). Estimation of consumer demand with stock-out based substitution: An application to vending machine products. Marketing Science, Volume 17(4):406-423.

Asker, J. (2004). Measuring cost advantages from exclusive dealing: An empirical study of beer distribution. mimeo, Dept. of Economics, Harvard University.

Bandyopadhyay, S., Rominger, A., and Basaviah, S. (2009). Developing a framework to improve retail category management through category captain arrangements. Journal of Retailing and Consumer Services, Forthcoming.

Basuroy, S., Mantrala, M. K., and Walters, R. G. (2001). The impact of category management on retailer prices and performance: Theory and evidence. Journal of Marketing, 65 (October):16-32. 
Berry, S., Levinsohn, J., and Pakes, A. (1995). Automobile prices in market equilibrium. Econometrica, 63:841-890.

Berry, S. and Pakes, A. (2005). The pure characteristics demand model. Working Paper, December.

Berto Villas-Boas, S. (2006). Vertical contracts between manufacturers and retailers: An empirical analysis. University of California, Berkeley, mimeo.

Besanko, D. and Doraszelski, U. (2004). Capacity dynamics and endogenous asymmetries in firm size. Rand Journal of Economics, 35:2349.

Besanko, D. A., Doraszelski, U., Lu, L. X., and Satterthwaite, M. A. (2008). Lumpy capacity investment and disinvestment dynamics. Working Paper, Harvard University.

Blattberg, R. C. and Fox, E. J. (1995). Category management: Getting started, guide 1. Washington, DC: Research Department, Food Marketing Institute.

Boatwright, P. and Nunes, J. C. (2001). Reducing assortment: An attribute-based approach. Journal of Marketing, 65(3):50-63.

Borle, S., Boatwright, P., Kadane, J. B., Nunez, J. C., and Shmueli, G. (2005). The effects of product assortment changes on customer retention. Marketing Science, 24(4):616-622.

Brenkers, R. and Verboven, F. (2004). Liberalizing a distribution system: The european car market. ULB mimeo.

Broniarczyk, S. M., Hoyer, W. D., and McAlister, L. (1998). Consumers' perceptions of the assortment offered in a grocery category: The impact of item reduction. Journal of Marketing Research, 35 (September):166-76.

Bruno, H. A. and Vilcassim, N. J. (2008). Structural demand estimation with varying product availability. Marketing Science, January.

Cachon, G. P. and Kok, A. G. (2007). Category management and coordination in retail assortment planning in the presence of basket shopping consumers. Management Science, 53 (June)(6):934-951. 
Chen, X. J., John, G., and Narasimhan, O. (2008). Assessing the consequences of a channel switch. Marketing Science, Articles in Advance:pp. 119.

Chernev, A. (2003). When more is less and less is more: The role of ideal point availability and assortment in consumer choice. Journal of Consumer Research, 30(2).

Chernev, A. (2006). Decision focus and consumer choice among assortments. Journal of Consumer Research, 33 (June):50-59.

Ciliberto, F. and Tamer, E. (2009). Market structure and multiple equilibria in airline markets. Econometrica, 77(6):1791-1828.

Conlon, C. T. and Mortimer, J. H. (2008). Demand estimation under incomplete product availability. Working Paper, October.

Conlon, C. T. and Mortimer, J. H. (2009). Demand estimation under incomplete product availability. Harvard Institute of Economic Research, Discussion Paper Number 2174.

Crawford, G. S. and Yurukoglu, A. (2009). The welfare effects of bundling in multichannel television markets. Working Paper, May.

Desrochers, D. M., Gundlach, G. T., and Foer, A. A. (2003). Analysis of antitrust challenges to category captain arrangements. Journal of Public Policy 83 Marketing, 22 (2):201-215.

Dhar, S. K., Hoch, S. J., and Nanda, K. (2001). Effective category management depends on the role of the category. Journal of Retailing, 77(4):165-184.

Draganska, M., Mazzeo, M., and Seim, K. (2008). Beyond plain vanilla: Modeling joint product assortment and pricing decisions. Working Paper, June.

Dube, J.-P. (Winter, 2004). Multiple discreteness and product differentiation: Demand for carbonated soft drinks. Marketing Science, 23(1):66-81.

Eizenberg, A. (2009). Upstream innovation and product variety in the u.s. home pc market. Working Paper, November.

FTC (2001). Public workshop on slotting allowances and other grocery marketing practices. February. 
Gajanan, S., Basuroy, S., and Beldona, S. (2007). Category management, product assortment, and consumer welfare. Marketing Letters, 18 (March):135-148.

Gooner, R. A., Morgan, N. A., and William D. Perreault, J. (2011). Is retail category management worth the effort (and does a category captain help or hinder)? Journal of Marketing, Postprint.

Gruen, T. W. and Shah, R. H. (2000). Determinants and outcomes of plan objectivity and implementation in category management relationships. Journal of Retailing, $76(4): 483-510$.

Gulati, R. and Wang, L. O. (2003). Size of the pie and share of the pie: Implications of network embeddedness and business relatedness for value creation and value appropriation in joint ventures. Research in the Sociology of Organization, 20:209-242.

Herderschee-Hunter, G. (2003). Antitrust and category captains roundtable discussion. American Antitrust Institute, June.

Ho, J., Ho, K., and Mortimer, J. H. (2011). The use of full-line forcing contracts in the video rental industry. Working Paper, January.

Ho, K. (2009). Insurer-provider networks in the medical care market. The American Economic Review, 99(1):393-430(38).

Hoch, S. J., Bradlow, E. T., and Wansink, B. (1999). The variety of an assortment. Marketing Science, 18(4):527-546.

Hoch, S. J., Bradlow, E. T., and Wansink, B. (2002). Rejoinder to "the variety of an assortment: An extension to the attribute-based approach". Marketing Science, $21(3): 342-346$.

Holcomb, R. (2010). Fapc-103 food industry overview-frozen pizza. OSU Fact Sheets.

Huaabner, A. H. and Kuhn, H. (2011). Quantitative models for retail category management: A review of assortment and shelf space planning in practice, software applications and science. Working Paper, February. 
Iyengar, S. S. and Lepper, M. R. (2000). When choice is demotivating: Can one desire too much of a good thing? Journal of Personality and Social Psychology, Vol 79(6):995-1006.

Jing, X. and Lewis, M. (2009). Managing stockouts in online retailing. Journal of Marketing Research, April.

Kalyanam, K., Borle, S., and Boatwright, P. (2007). Deconstructing each item's category contribution. Marketing Science, 26 (May-June)(3):327-341.

Kim, J., Allenby, G. M., and Rossi, P. E. (2002). Modeling consumer demand for variety. Marketing Science, 21 (Summer):229-250.

Klein, B. and Murphy, K. M. (2009). Exclusive dealing intensifies competition for distribution. Antitrust L.J.

Klein, B. and Wright, J. D. (2006). Antitrust analysis of category management: Conwood v. united states tobacco. Working Paper.

Kok, A. G. and Fisher, M. L. (2007). Demand estimation and assortment optimization under substitution: Methodology and application. Operations Research, Forthcoming.

Kok, A. G., Fisher, M. L., and Vaidyanathan, R. (2006). Assortment planning: Review of literature and industry practice. This paper is an invited chapter to appear in Retail Supply Chain Management, November.

Kurtulus, M. and Nakkas, A. (2010). Retail assortment planning under category captainship. Working Paper.

Kurtulus, M. and Toktay, L. B. (2008). Category captainship: Outsourcing retail category management. Working Paper.

Kurtulus, M. and Toktay, L. B. (2011). Category captainship vs. retailer category management under limited retail shelf space. Production and Operations Management, 20(1):47-56.

Lafontaine, F. and Slade, M. (2005). Exclusive contracts and vertical restraints: Empirical evidence and public policy. Journal of Economic Literature, September. 
Lafontaine, F. and Slade, M. (2007). Vertical integration and firm boundaries : The evidence. Journal of Economic Literature.

Leary, T. B. (2003). A second look at category management. American Antitrust Institute.

Lee, R. S. (2009). Vertical integration and exclusivity in platform and two-sided markets. Working Paper, April.

Lindblom, A. and Olkkonen, R. (2008). An analysis of suppliers roles in category management collaboration. Journal of Retailing and Consumer Services, 15(1):1 8.

MacDonald, G. and Ryall, M. D. (2004). How do value creation and competition determine whether a firm appropriates value? Management Science, 50(10):1319-1333.

Maddah, B. and Bish, E. K. (2007). Joint pricing, assortment, and inventory decisions for a retailer's product line. Naval Research Logistics, 54(3):315-330.

Mantrala, M. K., Levy, M., Kahn, B. E., Fox, E. J., Gaidarev, P., Dankworth, B., and Shah, D. (2009). Why is assortment planning so difcult for retailers? a framework and research agenda. Journal of Retailing, 85 (1):7183.

McAlister, L. and Pessemier, E. (1982). Variety seeking behavior: An interdisciplinary review. Journal of Consumer Research, 9(3):311-322.

McLaughlin, E. W. and Hawkes, G. F. (1994). Category management: Current status and future outlook. Food Industry Management, December (28):1-33.

Mishra, B. K. and Raghunathan, S. (2004). Retailer- vs. vendor-managed inventory and brand competition. Management Science, 50 (April)(4):445-457.

Misra, K. (2008). Understanding retail assortments in competitive markets. Working Paper, June.

Misra, K., Nijs, V., and Hansen, K. (2009). Selecting a category captain: The impact on manufacturers, retailers, and consumers. Working Paper, October. 
Morgan, N. A., Kaleka, A., and Gooner, R. A. (2007). Focal supplier opportunism in supermarket retailer category management. Journal of Operations Management, 25:512-527.

Mortimer, J. H. (2004). Vertical contracts in the video rental industry. Working Paper, April.

Musalem, A., Olivares, M., Bradlow, E. T., Terwiesch, C., and Corsten, D. (2010). Structural estimation of the effect of out-of-stocks. Working Paper, January.

Nevo, A. (2000a). Mergers with differentiated products: The case of the ready-to-eat cereal industry. The RAND Journal of Economics, 31:395421.

Nevo, A. (2000b). A practitioners guide to estimation of random-coefficients logit models of demand. Journal of Economics and Managements Strategy, 9:513548.

Nevo, A. (2001). Measuring market power in the ready-to-eat cereal industry. Econometrica, 69:307342.

Nosko, C. (2010). Competition and quality choice in the cpu market. Working Paper, November.

Pakes, A., Porter, J., Ho, K., and Ishii, J. (2006). Moment inequalities and their application. Working Paper, November.

Seim, K. (2006). An empirical model of firm entry with endogenous product-type choices. The RAND Journal of Economics, 37(3):619640.

Slade, M. E. (2000). Regulating manufacturers and their exclusive retailers. in Foundations of Competition Policy, Morten Berg and Einar Hope (eds.), London: Routledge,:133149.

Sloot, L. M., Fok, D., and Verhoef, P. C. (2006). The short- and long-term impact of an assortment reduction on category sales. Journal of Marketing Research, 43(4:536-548.

Snider, C. (2009). Predatory incentives and predation policy: The american airlines case. Working Paper. 
Steiner, R. L. (2000). The third relevant market. The Antitrust Bulletin, 45 (Fall):71959.

Subramanian, U., Raju, J. S., Dhar, S. K., and Wang, Y. (2010). Competitive consequences of using a category captain. Management Science, 56 (October)(10):17391765.

van Ryzin, G. and Mahajan, S. (1999). On the relationship between inventory costs and variety benefits in retail assortments. Management Science, 45:1496-1509.

Vulcano, G., Ryzin, G. v., and Ratliff, R. (2009). Estimating primary demand for substitutable products from sales transaction data. Working Paper, May.

Yurukoglu, A. and Crawford, G. S. (2011). The welfare effects of bundling in multichannel television markets. American Economic Review, April. 


\section{Appendix A}

\section{Tables \& Figures}

\section{A.1 Descriptive Statistics}

Table A.1: Variable Description and Descriptive Statistics

\begin{tabular}{lccccc}
\hline \hline Variable & Description & Mean & Std Dev & Minimum & Maximum \\
\hline Price & \$/unit & 5.75 & 1.35 & 2.71 & 10.99 \\
& & & & & \\
\hline Topping & & & & & \\
Meat & Dummy & 0.16 & 0.37 & 0 & 1 \\
Vegetables & Dummy & 0.29 & 0.45 & 0 & 1 \\
Cheese & Dummy & 0.28 & 0.45 & 0 & 1 \\
Sausage & Dummy & 0.15 & 0.36 & 0 & 1 \\
& & & & & 1 \\
\hline Crust & & & & & 1 \\
Regular & Dummy & 0.03 & 0.17 & 0 & 1 \\
Crispy & Dummy & 0.26 & 0.44 & 0 & 32.7 \\
\hline Size & & & & & \\
\hline Brand & & 17.49 & 8.49 & 1 & \\
\hline
\end{tabular}




\begin{tabular}{llllll} 
DiGiorno's & Dummy & 0.47 & 0.50 & 0 & 1 \\
California & Dummy & 0.14 & 0.35 & 0 & 1 \\
Pizza Kitchen & & & & & \\
Private Label & Dummy & 0.02 & 0.13 & 0 & 1 \\
Freschetta & Dummy & 0.19 & 0.39 & 0 & 1 \\
Amy's & Dummy & 0.09 & 0.29 & 0 & 1 \\
Newman's & Dummy & 0.04 & 0.19 & 0 & 1 \\
Kashi & Dummy & 0.05 & 0.23 & 0 & 1 \\
\hline \hline
\end{tabular}

Summary Statistics from Baltimore geographic market 
Table A.2: Descriptive Results by Markets

\begin{tabular}{|c|c|c|c|c|c|c|}
\hline Geographic Market & \# of chains & \# of CC chains & Market Size (hh) & Avg Pizza Consumption & $\begin{array}{l}\text { \# of SKUs in Market } \\
\text { (Assortment Superset) }\end{array}$ & $\begin{array}{l}\text { \# of SKUs in Chain } \\
\text { (Assortment Carried) }\end{array}$ \\
\hline Boston & 3 & 2 & $1,760,584$ & 1.64 & 97 & 64 \\
\hline Erie & 2 & 1 & 110,413 & 1.02 & 60 & 48 \\
\hline New York & 5 & 4 & $6,918,950$ & 0.31 & 74 & 53 \\
\hline Poughkeepsie & 4 & 3 & 233,890 & 0.97 & 76 & 52 \\
\hline
\end{tabular}

Averages are across chain-quarter. Avg Pizza Consumption is defined as the ratio of total pizza sales by market size 
Table A.3: Reduced Form Results - Brand Level

\begin{tabular}{|c|c|c|c|}
\hline Coefficients & BDI (Unit Sales) & Assortment Share & Brand Price \\
\hline \multirow[t]{2}{*}{ Avg Brand Price } & $-9.40^{* * *}$ & $-0.40^{* * *}$ & - \\
\hline & $(0.21)$ & $(0.04)$ & \\
\hline \multirow[t]{2}{*}{ Category Captain } & $3.56^{* * *}$ & $0.20^{* * *}$ & $0.05^{* * *}$ \\
\hline & $(0.26)$ & $(0.05)$ & $(0.00)$ \\
\hline \multirow[t]{2}{*}{$\mathrm{ACV}$ (\% stores) } & $0.04^{* * *}$ & -0.00 & $0.00^{* * *}$ \\
\hline & $(0.00)$ & $(0.00)$ & $(0.00)$ \\
\hline \multirow[t]{2}{*}{ Feature } & $0.86^{* * *}$ & 0.08 & $0.02 * * *$ \\
\hline & $(0.24)$ & $(0.05)$ & $(0.00)$ \\
\hline \multirow[t]{2}{*}{ Display } & $1.18^{* * *}$ & -0.02 & $-0.07^{* * *}$ \\
\hline & $(0.24)$ & $(0.05)$ & $(0.00)$ \\
\hline \multirow[t]{2}{*}{ Feature \& Display } & $3.07^{* * *}$ & $0.28^{* * *}$ & $-0.04^{* * *}$ \\
\hline & $(0.28)$ & $(0.06)$ & $(0.00)$ \\
\hline \multirow[t]{2}{*}{ Brand shelf share (\# SKUs) } & $0.78^{* * *}$ & - & - \\
\hline & $(0.15)$ & & \\
\hline \multicolumn{4}{|l|}{ Brand Dummies } \\
\hline \multirow[t]{2}{*}{ DiGiorno's } & $15.59^{* * *}$ & $4.70^{* * *}$ & $1.96^{* * *}$ \\
\hline & $(0.44)$ & $(0.12)$ & $(0.00)$ \\
\hline \multirow[t]{2}{*}{ California Pizza Kitchen } & $-7.25^{* * *}$ & $-1.47^{* * *}$ & $1.75^{* * *}$ \\
\hline & $(0.63)$ & $(0.12)$ & $(0.00)$ \\
\hline \multirow[t]{2}{*}{ Freschetta } & $27.49^{* * *}$ & $-1.11^{* * *}$ & $1.98^{* * *}$ \\
\hline & $(0.28)$ & $(0.13)$ & $(0.00)$ \\
\hline \multirow[t]{2}{*}{ Constant } & $115.31^{* * *}$ & $29.29^{* * *}$ & 3.76 \\
\hline & $(1.74)$ & $(0.27)$ & $(0.02)$ \\
\hline \multicolumn{4}{|l|}{$\mathrm{n}=51,247$} \\
\hline Adjusted $R^{2}$ & 0.82 & 0.86 & 0.60 \\
\hline
\end{tabular}

Category Captain is a dummy variable that indicates whether brand is owned by captain. The above regression also includes dummy variables for chain, year and quarter which are not shown. Standard errors are in parantheses, ${ }^{* * *} p<0.01,{ }^{* *} p<0.05,{ }^{*} p<0.1$ 
Table A.4: Reduced Form Results

\begin{tabular}{|c|c|c|c|c|}
\hline \multirow[t]{2}{*}{ Coefficients } & \multicolumn{2}{|c|}{ Linear Regression } & \multicolumn{2}{|c|}{ Simultaneous Equations } \\
\hline & Assortment share & Avg Price & Assortment share & Avg Price \\
\hline \multirow[t]{2}{*}{ Avg Price } & $0.87^{* * *}$ & - & $-3.54^{* * *}$ & \\
\hline & $(0.28)$ & & $(.85)$ & \\
\hline \multirow[t]{2}{*}{ Assortment Share } & - & $.08^{* * *}$ & & .07 \\
\hline & & $(0.02)$ & & $(0.10)$ \\
\hline \multirow[t]{2}{*}{ Market Share } & $19.20^{* * *}$ & $-1.53^{* *}$ & $19.15^{* *}$ & -1.49 \\
\hline & $(1.87)$ & $(0.62)$ & $(2.90)$ & $(2.15)$ \\
\hline \multirow[t]{2}{*}{ Category Captain } & $1.32^{* * *}$ & -0.15 & $1.33^{* *}$ & - \\
\hline & $(0.46)$ & $(0.12)$ & $(.02)$ & \\
\hline \multirow[t]{2}{*}{ Competitor Price } & - & $0.48^{* * *}$ & & $0.42^{* * *}$ \\
\hline & & $(0.13)$ & & $(0.11)$ \\
\hline \multirow[t]{2}{*}{ HHI } & - & $0.76^{*}$ & & $1.34^{* *}$ \\
\hline & & $(0.39)$ & & $(0.66)$ \\
\hline \multirow[t]{2}{*}{ Market Size } & $.001^{*}$ & - & $0.00^{* *}$ & - \\
\hline & $(0.00)$ & 0.00 & & \\
\hline \multicolumn{5}{|l|}{ Brand Dummies } \\
\hline \multirow[t]{2}{*}{ DiGorno's } & $-4.09^{* * *}$ & $-2.17^{* * *}$ & $-8.95^{* * *}$ & $-2.14^{* * *}$ \\
\hline & $(1.20)$ & $(0.29)$ & $(1.95)$ & $(0.32)$ \\
\hline \multirow[t]{2}{*}{ California Pizza Kitchen } & $5.25 * * *$ & $-1.74^{* * *}$ & $7.01^{* * *}$ & -1.73 \\
\hline & $(1.24)$ & $(0.38)$ & $(1.34)$ & $(1.12)$ \\
\hline \multirow[t]{2}{*}{ Freschetta } & $-4.24^{* * *}$ & $-1.06^{* * *}$ & $-5.12^{* * *}$ & -1.12 \\
\hline & $(0.63)$ & $(0.20)$ & $(0.90)$ & $(0.22)$ \\
\hline \multirow[t]{2}{*}{ Amy's } & $-2.28^{* * *}$ & $-0.86^{* * *}$ & $-1.67^{* *}$ & $-0.95^{* * *}$ \\
\hline & $(0.57)$ & $(0.21)$ & $(0.80)$ & $(0.24)$ \\
\hline \multirow[t]{2}{*}{ Newman's } & $-0.91^{*}$ & $0.85^{* * *}$ & $5.78^{* *}$ & $0.85^{* * *}$ \\
\hline & $(1.02)$ & $(0.20)$ & $(2.01)$ & $(0.32)$ \\
\hline \multirow[t]{2}{*}{ Kashi } & $-3.24^{* * *}$ & $-0.71^{* * *}$ & $-2.80 * *$ & $-0.74 * * *$ \\
\hline & $(0.85)$ & $(0.23)$ & (1.18) & $(0.23)$ \\
\hline
\end{tabular}




\begin{tabular}{lllll} 
Constant & $\begin{array}{l}4.60^{*} \\
(1.62)\end{array}$ & $\begin{array}{l}3.19^{* * *} \\
(0.81)\end{array}$ & $\begin{array}{l}23.13^{* * *} \\
(4.54)\end{array}$ & $\begin{array}{l}3.30^{* * *} \\
(1.00)\end{array}$ \\
\hline $\mathrm{n}=220$ & & & & \\
Adjusted $R^{2}$ & 0.90 & 0.61 & 0.82 & 0.60 \\
\hline
\end{tabular}

Category Captain is a dummy variable that indicates whether brand is owned by captain. Standard errors are in parantheses, ${ }^{* * *} p<0.01,{ }^{* *} p<0.05,{ }^{*} p<0.1$

Table A.5: Chain 1: Captaincy Change from Firm A to Retail management

\begin{tabular}{l|cc|cc}
\hline \hline & \multicolumn{2}{|c}{ BDI (Unit Sales) } & Assortment Share (\%) \\
\hline Firm $\downarrow$ & Firm A-CC & Retailer-CC & Firm A-CC & Retailer-CC \\
\hline & 123.30 & 110.72 & 21.6 & 19.5 \\
Firm A & 125.82 & 119.24 & 5.4 & 9.1 \\
Firm B & & & & \\
\hline \hline
\end{tabular}

Table A.6: Chain 2: Captaincy Change from Firm B to Firm A

\begin{tabular}{l|cc|cc}
\hline \hline & \multicolumn{2}{|c}{ BDI (Unit Sales) } & \multicolumn{2}{c}{ Assortment Share (\%) } \\
\hline Firm $\downarrow$ & Firm B-CC & Firm A-CC & Firm B-CC & Firm A-CC \\
\hline & & & & \\
Firm A & 75.98 & 87.13 & 15.5 & 17.2 \\
& 192.77 & 55.40 & 9.3 & 8.8 \\
\hline \hline
\end{tabular}




\section{A.2 Demand Results}

Table A.7: Demand Results - Baltimore Market

\begin{tabular}{|c|c|c|c|c|}
\hline Coefficients & Logit_OLS & Logit_IV & Random Coefficients & Heterogeneity $(\sigma)$ \\
\hline Price & $\begin{array}{c}-0.31 * * * \\
(0.03)\end{array}$ & $\begin{array}{c}-0.35 \text { *** } \\
(0.04)\end{array}$ & $\begin{array}{c}-2.38 * * * \\
(0.06)\end{array}$ & $\begin{array}{c}1.69 \text { *** } \\
(0.00)\end{array}$ \\
\hline \multicolumn{5}{|l|}{ Topping } \\
\hline Size & $\begin{array}{c}0.06^{* * *} \\
(0.01)\end{array}$ & $\begin{array}{c}0.07^{* * *} \\
(0.01)\end{array}$ & $\begin{array}{c}0.10 * * * \\
(0.01)\end{array}$ & $\begin{array}{c}0.11^{* * *} \\
(0.00)\end{array}$ \\
\hline Exotic & $\begin{array}{c}0.33^{* * *} \\
(0.10)\end{array}$ & $\begin{array}{c}0.34 * * * \\
(0.10)\end{array}$ & $\begin{array}{c}-0.35 * * * \\
(0.14)\end{array}$ & $\begin{array}{c}1.51 \text { *** } \\
(0.00)\end{array}$ \\
\hline Cheese & $\begin{array}{c}-0.03 \\
(0.06)\end{array}$ & $\begin{array}{c}-0.03 \\
(0.06)\end{array}$ & $\begin{array}{c}0.17 * \\
(0.09)\end{array}$ & \\
\hline Vegetables & $\begin{array}{c}-0.31 * * * \\
(0.07)\end{array}$ & $\begin{array}{c}-0.31 \text { *** } \\
(0.07)\end{array}$ & $\begin{array}{c}-0.55 * * * \\
(0.10)\end{array}$ & \\
\hline Fruit & $\begin{array}{c}0.28 * \\
(0.16)\end{array}$ & $\begin{array}{c}0.28 * \\
(0.16)\end{array}$ & $\begin{array}{c}-0.21 \\
(0.23)\end{array}$ & \\
\hline Pepporoni & $\begin{array}{c}0.21^{* * *} \\
(0.07)\end{array}$ & $\begin{array}{c}0.20^{* * *} \\
(0.07)\end{array}$ & $\begin{array}{l}0.23^{* *} \\
(0.11)\end{array}$ & \\
\hline Sausage & $\begin{array}{c}-0.52 * * * \\
(0.10)\end{array}$ & $\begin{array}{c}-0.52 * * * \\
(0.10)\end{array}$ & $\begin{array}{c}-0.72^{* * *} \\
(0.14)\end{array}$ & \\
\hline Meat & $\begin{array}{c}-0.41^{* * *} \\
(0.09)\end{array}$ & $\begin{array}{c}-0.40 * * * \\
(0.09)\end{array}$ & $\begin{array}{c}-0.52 * * * \\
(0.14)\end{array}$ & \\
\hline Crust & & & & \\
\hline Regular & $\begin{array}{c}0.45^{* * *} \\
(0.08)\end{array}$ & $\begin{array}{c}0.46^{* * *} \\
(0.09)\end{array}$ & $\begin{array}{c}1.40 * * * \\
(0.12)\end{array}$ & \\
\hline Crispy & $\begin{array}{c}0.04 \\
(0.08)\end{array}$ & $\begin{array}{c}0.01 \\
(0.09)\end{array}$ & $\begin{array}{c}0.22 \\
(0.13)\end{array}$ & \\
\hline Brand & & & & \\
\hline DiGiorno's & -0.11 & -0.11 & -0.24 & \\
\hline
\end{tabular}




\begin{tabular}{lccc} 
& $(0.10)$ & $(0.10)$ & $(0.15)$ \\
California Pizza Kitchen & -0.02 & 0.00 & $0.39 * *$ \\
& $(0.12)$ & $(0.12)$ & $(0.18)$ \\
Freschetta & -0.01 & 0.01 & $0.52 * * *$ \\
& $(0.11)$ & $(0.11)$ & $(0.16)$ \\
Amy's & $-0.41 * *$ & -0.31 & $-1.92 * * *$ \\
& $(0.17)$ & $(0.20)$ & $(0.28)$ \\
Newman's & $-0.34 * *$ & $-0.31 *$ & -0.23 \\
& $(0.16)$ & $(0.16)$ & $(0.23)$ \\
\hline
\end{tabular}

Chain,quarter and year dummy variables along with other interactions variables not reported for conciseness. Standard errors are in parantheses, *** $p<0.01,{ }^{* *} p<0.05,{ }^{*} p<0.1$

Table A.8: Demand Results - Boston Market

\begin{tabular}{lcccc}
\hline \hline Coefficients & Logit_OLS & Logit_IV & Random Coefficients & Heterogeneity $(\sigma)$ \\
\hline \hline Price & $-0.14^{* * *}$ & $-0.29 * * *$ & $-0.30 * * *$ & $0.04 * * *$ \\
Topping & $(0.06)$ & $(0.07)$ & $(0.07)$ & $(0.00)$ \\
Size & & & & $0.00 * * *$ \\
& $0.02 * *$ & $0.04 * * *$ & $0.04 * * *$ & $(0.00)$ \\
Exotic & $(0.01)$ & $(0.01)$ & $(0.01)$ & $(1.38)$ \\
& $0.95 * * *$ & $0.95 * * *$ & $0.95 * * *$ & $(0.16)$ \\
Cheese & $(0.16)$ & $(0.16)$ & 0.04 & \\
& 0.03 & 0.04 & $(0.10)$ & \\
Vegetables & $(0.10)$ & $(0.10)$ & -0.02 & \\
& 0.00 & -0.01 & $0.12)$ & \\
Fruit & $(0.12)$ & $(0.12)$ & 0.15 & \\
& 0.14 & 0.16 & $(0.25)$ & \\
Pepporoni & $(0.25)$ & $(0.25)$ & 0.06 & $(0.13)$ \\
Sausage & 0.10 & 0.06 & $-0.64 * * *$ &
\end{tabular}




\begin{tabular}{lccc} 
& $(0.17)$ & $(0.17)$ & $(0.17)$ \\
Meat & $-0.47^{* * *}$ & $-0.45 * * *$ & $-0.45 * * *$ \\
Crust & $(0.15)$ & $(0.15)$ & $(0.15)$ \\
Regular & & & \\
& 0.15 & 0.14 & 0.14 \\
Crispy & $(0.14)$ & $(0.14)$ & $(0.14)$ \\
& $0.71 * * *$ & $0.55 * * *$ & $0.55 * * *$ \\
Brand & $(0.15)$ & $(0.16)$ & $(0.16)$ \\
DiGiorno's & & & $-1.10 * * *$ \\
& $-1.11 * * *$ & $-1.10 * * *$ & $(0.15)$ \\
California Pizza Kitchen & $-0.88 * * *$ & $-0.71 * * *$ & $-0.70 * * *$ \\
& $(0.15)$ & $(0.15)$ & $(0.21)$ \\
Freschetta & $-0.89 * * *$ & $-0.85 * * *$ & $-0.84 * * *$ \\
& $(0.14)$ & $(0.14)$ & $(0.14)$ \\
Amy's & $-1.44 * * *$ & $-1.11 * * *$ & $-1.10 * * *$ \\
Newman's & $(0.25)$ & $(0.26)$ & $(0.26)$ \\
& $-0.65 * * *$ & $-0.54 * *$ & $-0.53 * *$ \\
\hline \hline
\end{tabular}

Chain,quarter and year dummy variables along with other interactions variables not reported for conciseness. Standard errors are in parantheses, ${ }^{* * *} p<0.01,{ }^{* *} p<0.05,{ }^{*} p<0.1$

Table A.9: Demand Results - Erie Market

\begin{tabular}{lcccc}
\hline \hline Coefficients & Logit_OLS & Logit_IV & Random Coefficients & Heterogeneity $(\sigma)$ \\
\hline \hline Price & & & & \\
& $\left(0.40^{* * *}\right.$ & $-0.42^{* * *}$ & $-2.03^{* * *}$ & $2.01 * * *$ \\
Topping & $(0.05)$ & $(0.09)$ & $(0.80)$ \\
Size & $0.07^{* * *}$ & $0.07^{* * *}$ & $0.10^{* * *}$ & $0.16^{* * *}$ \\
& $(0.01)$ & $(0.01)$ & $(0.02)$ & $(0.00)$ \\
Exotic & $0.59^{* * *}$ & $0.60^{* * *}$ & $-29.80^{* * *}$ & $2.20 * * *$
\end{tabular}




$\begin{array}{lccc} & (0.14) & (0.14) & (0.28) \\ \text { Cheese } & -0.08 & -0.09 & -0.30 \\ \text { Vegetables } & (0.10) & (0.10) & (0.21) \\ & -0.14 & -0.14 & -0.06 \\ \text { Fruit } & (0.10) & (0.10) & (0.20) \\ & -0.39 & -0.36 & 1.77 * * * \\ \text { Pepporoni } & (0.30) & (0.30) & (0.61) \\ & 0.61 * * * & 0.61 * * * & 0.54 * * * \\ \text { Sausage } & (0.10) & (0.10) & (0.21) \\ & -0.84 * * * & -0.85 * * * & -0.98 * * * \\ \text { Meat } & (0.10) & (0.10) & (0.21) \\ & -0.25 & -0.26 & -0.27 \\ & (0.15) & (0.15) & (0.31)\end{array}$

\section{Crust}

Regular

$\begin{array}{ccc}-0.11 & -0.09 & 0.60 * * \\ (0.12) & (0.12) & (0.25) \\ 0.14 & 0.13 & 0.58^{* * *} \\ (0.10) & (0.10) & (0.21)\end{array}$

\section{Brand}

DiGiorno's

$$
\begin{array}{ccc}
-0.28 * * * & -0.28 * * * & -0.60 * * * \\
(0.09) & (0.09) & (0.19)
\end{array}
$$

$\begin{array}{llll}\text { California Pizza Kitchen } & 0.20 & 0.23 & 0.35\end{array}$

\begin{tabular}{lccc} 
Freschetta & $-0.31 * * *$ & $-0.30 * * *$ & -0.03 \\
\multirow{2}{*}{ Amy's } & $(0.12)$ & $(0.12)$ & $(0.24)$ \\
& 0.00 & 0.00 & 0.00 \\
Newman's & $(0.00)$ & $(0.00)$ & $(0.00)$ \\
& -0.16 & -0.14 & -0.33 \\
& $(0.23)$ & $(0.23)$ & $(0.48)$ \\
\hline
\end{tabular}

Chain,quarter and year dummy variables along with other interactions variables not reported for conciseness. Standard errors are in parantheses, *** $p<0.01,{ }^{* *} p<0.05,{ }^{*} p<0.1$ 
Table A.10: Demand Results - Las Vegas Market

\begin{tabular}{|c|c|c|c|c|}
\hline Coefficients & Logit_OLS & Logit_IV & Random Coefficients & Heterogeneity $(\sigma)$ \\
\hline Price & $\begin{array}{c}-0.36 * * * \\
(0.03)\end{array}$ & $\begin{array}{c}-0.37 * * * \\
(0.04)\end{array}$ & $\begin{array}{c}-3.21 * * * \\
(0.07)\end{array}$ & $\begin{array}{c}2.55 * * * \\
(0.67)\end{array}$ \\
\hline \multicolumn{5}{|l|}{ Topping } \\
\hline Size & $\begin{array}{c}0.08^{* * *} \\
(0.01)\end{array}$ & $\begin{array}{c}0.08^{* * *} \\
(0.01)\end{array}$ & $\begin{array}{c}0.10^{* * *} \\
(0.01)\end{array}$ & $\begin{array}{l}0.16^{* *} \\
(0.05)\end{array}$ \\
\hline Exotic & $\begin{array}{l}0.16^{* *} \\
(0.08)\end{array}$ & $\begin{array}{l}0.17^{* *} \\
(0.08)\end{array}$ & $\begin{array}{c}-1.24 * * * \\
(0.14)\end{array}$ & $\begin{array}{c}2.31^{* * *} \\
(0.27)\end{array}$ \\
\hline Cheese & $\begin{array}{c}-0.16^{* * *} \\
(0.06)\end{array}$ & $\begin{array}{c}-0.16^{* * *} \\
(0.06)\end{array}$ & $\begin{array}{c}-0.18 \\
(0.10)\end{array}$ & \\
\hline Vegetables & $\begin{array}{c}-0.21^{* * *} \\
(0.06)\end{array}$ & $\begin{array}{c}-0.20 * * * \\
(0.06)\end{array}$ & $\begin{array}{c}-0.39 * * * \\
(0.11)\end{array}$ & \\
\hline Fruit & $\begin{array}{c}-0.50 * * * \\
(0.10)\end{array}$ & $\begin{array}{c}-0.50 * * * \\
(0.10)\end{array}$ & $\begin{array}{c}-1.19 \text { *** } \\
(0.17)\end{array}$ & \\
\hline Pepporoni & $\begin{array}{c}0.16^{* * *} \\
(0.06)\end{array}$ & $\begin{array}{c}0.16^{* * *} \\
(0.06)\end{array}$ & $\begin{array}{c}0.05 \\
(0.11)\end{array}$ & \\
\hline Sausage & $\begin{array}{c}-0.12 \\
(0.08)\end{array}$ & $\begin{array}{c}-0.12 \\
(0.08)\end{array}$ & $\begin{array}{c}-0.37^{* * *} \\
(0.14)\end{array}$ & \\
\hline Meat & $\begin{array}{c}0.03 \\
(0.08)\end{array}$ & $\begin{array}{c}0.02 \\
(0.08)\end{array}$ & $\begin{array}{l}-0.25 * \\
(0.14)\end{array}$ & \\
\hline Crust & & & & \\
\hline Regular & $\begin{array}{c}0.27 * * * \\
(0.08)\end{array}$ & $\begin{array}{c}0.28^{* * *} \\
(0.09)\end{array}$ & $\begin{array}{c}1.28 * * * \\
(0.15)\end{array}$ & \\
\hline Crispy & $\begin{array}{c}0.12 \\
(0.08)\end{array}$ & $\begin{array}{c}0.11 \\
(0.08)\end{array}$ & $\begin{array}{c}0.66^{* * *} \\
(0.14)\end{array}$ & \\
\hline Brand & & & & \\
\hline DiGiorno's & $\begin{array}{c}-0.05 \\
(0.09)\end{array}$ & $\begin{array}{c}-0.04 \\
(0.09)\end{array}$ & $\begin{array}{c}-0.58 * * * \\
(0.16)\end{array}$ & \\
\hline California Pizza Kitchen & $0.25 * *$ & $0.26 * *$ & 0.30 & \\
\hline
\end{tabular}




\begin{tabular}{lccc} 
& $(0.11)$ & $(0.11)$ & $(0.20)$ \\
Freschetta & -0.08 & -0.07 & $0.52 * * *$ \\
\multirow{2}{*}{ Amy's } & $(0.10)$ & $(0.10)$ & $(0.18)$ \\
& 0.22 & 0.24 & -0.83 \\
Newman's & $(0.37)$ & $(0.37)$ & $(0.68)$ \\
& $-0.49 * *$ & $-0.47 *$ & $-1.36 * * *$ \\
& $(0.24)$ & $(0.24)$ & $(0.43)$ \\
\hline
\end{tabular}

Chain,quarter and year dummy variables along with other interactions variables not reported for conciseness. Standard errors are in parantheses, ${ }^{* * *} p<0.01,{ }^{* *} p<0.05,{ }^{*} p<0.1$

Table A.11: Demand Results - Los Angeles Market

\begin{tabular}{|c|c|c|c|c|}
\hline Coefficients & Logit_OLS & Logit_IV & Random Coefficients & Heterogeneity $(\sigma)$ \\
\hline Price & $\begin{array}{c}-0.56 * * * \\
(0.04)\end{array}$ & $\begin{array}{c}-0.60 * * * \\
(0.06)\end{array}$ & $\begin{array}{c}-4.07 * * * \\
(0.14)\end{array}$ & $\begin{array}{l}3.63^{* *} \\
\left(1.77^{2}\right)\end{array}$ \\
\hline \multicolumn{5}{|l|}{ Topping } \\
\hline Size & $\begin{array}{c}0.08^{* * *} \\
(0.01)\end{array}$ & $\begin{array}{c}0.09 * * * \\
(0.01)\end{array}$ & $\begin{array}{c}0.09^{* * *} \\
(0.02)\end{array}$ & $\begin{array}{c}0.05 * * * \\
(0.00)\end{array}$ \\
\hline Exotic & $\begin{array}{c}0.42^{* * *} \\
(0.12)\end{array}$ & $\begin{array}{c}0.45^{* * *} \\
(0.12)\end{array}$ & $\begin{array}{c}-27.42^{* * *} \\
(0.31)\end{array}$ & $\begin{array}{c}26.20^{* * *} \\
(0.27)\end{array}$ \\
\hline Cheese & $\begin{array}{c}-0.28 * * * \\
(0.08)\end{array}$ & $\begin{array}{c}-0.28^{* * *} \\
(0.08)\end{array}$ & $\begin{array}{c}0.56 \text { *** } \\
(0.21)\end{array}$ & \\
\hline Vegeatables & $\begin{array}{c}-0.20 * * \\
(0.09)\end{array}$ & $\begin{array}{c}-0.19 * * \\
(0.09)\end{array}$ & $\begin{array}{c}-0.07 \\
(0.23)\end{array}$ & \\
\hline Fruit & $\begin{array}{c}-0.73^{* * *} \\
(0.15)\end{array}$ & $\begin{array}{c}-0.72^{* * *} \\
(0.15)\end{array}$ & $\begin{array}{c}-0.51 \\
(0.38)\end{array}$ & \\
\hline Pepporoni & $\begin{array}{c}0.41 * * * \\
(0.09)\end{array}$ & $\begin{array}{c}0.42^{* * *} \\
(0.09)\end{array}$ & $\begin{array}{c}1.38^{* * *} \\
(0.23)\end{array}$ & \\
\hline Sausage & $\begin{array}{c}-0.48 * * * \\
(0.11)\end{array}$ & $\begin{array}{c}-0.49 * * * \\
(0.11)\end{array}$ & $\begin{array}{c}-2.07 * * * \\
(0.28)\end{array}$ & \\
\hline Meat & $0.54 * * *$ & $0.53^{* * *}$ & $0.78 * * *$ & \\
\hline
\end{tabular}




$$
(0.12) \quad(0.12) \quad(0.31)
$$

\section{Crust}

Regular

$$
\begin{array}{ccc}
0.22 * & 0.24 * & 1.28 * * * \\
(0.12) & (0.13) & (0.31) \\
0.23 * & 0.22 & 1.06 * * * \\
(0.13) & (0.13) & (0.32)
\end{array}
$$

Crispy

\section{Brand}

DiGiorno's

$$
-0.23
$$

$-1.20 * * *$

California Pizza Kitchen

$$
\text { ( } 0.14) \quad(0.14)
$$

\section{Caifornia Pizza Kitchen}

0.13

0.17

$-1.03 * *$

$$
(0.18)
$$

Freschetta

$$
\begin{array}{cc}
-0.44 * * * & -0.41 * * \\
(0.17) & (0.17)
\end{array}
$$$$
-0.82 \text { * }
$$

Amy's

$-0.34$

$-0.22$

$-14.05 * * *$

$\left(\begin{array}{ll}0.37) \quad(0.39) \\ 0.16\end{array}\right.$

( 0.97 )

Newman's

$\begin{array}{ll}0.16 & 0.24 \\ (0.41) & (0.42)\end{array}$

$-5.37 * * *$

$(1.05)$

Chain,quarter and year dummy variables along with other interactions variables not reported for conciseness. Standard errors are in parantheses, ${ }^{* * *} p<0.01,{ }^{* *} p<0.05,{ }^{*} p<0.1$

Table A.12: Demand Results - New York Market

\begin{tabular}{lcccc}
\hline \hline Coefficients & Logit_OLS & Logit_IV & Random Coefficients & Heterogeneity $(\sigma)$ \\
\hline \hline Price & & & & \\
& $(0.03)$ & $(0.05)$ & $(-0.06)$ & $1.13^{* * *}$ \\
Topping & & & & $\left(0.45^{* * *}\right.$ \\
Size & $0.04^{* * *}$ & $0.05^{* * *}$ & $0.05^{* * *}$ & $-0.07 * * *$ \\
& $(0.01)$ & $(0.01)$ & $(0.01)$ & $(0.00)$ \\
Exotic & $0.37^{* * *}$ & $0.40^{* * *}$ & 0.08 & $1.34 * * *$ \\
& $(0.12)$ & $(0.12)$ & $(0.14)$ & $(0.27)$ \\
Cheese & $0.32^{* * *}$ & $0.32 * * *$ & $0.31 * * *$ &
\end{tabular}




\begin{tabular}{|c|c|c|c|}
\hline & $(0.08)$ & $(0.08)$ & $(0.09)$ \\
\hline \multirow[t]{2}{*}{ Vegeatables } & -0.06 & -0.06 & -0.14 \\
\hline & $(0.09)$ & $(0.09)$ & $(0.11)$ \\
\hline \multirow[t]{2}{*}{ Fruit } & 0.22 & 0.30 & -0.51 \\
\hline & $(0.26)$ & $(0.26)$ & $(0.30)$ \\
\hline \multirow[t]{2}{*}{ Pepporoni } & 0.11 & 0.07 & 0.11 \\
\hline & $(0.10)$ & $(0.10)$ & $(0.11)$ \\
\hline \multirow[t]{2}{*}{ Sausage } & $-0.32 * *$ & $-0.34 * * *$ & $-0.52 * * *$ \\
\hline & $(0.13)$ & $(0.13)$ & $(0.15)$ \\
\hline \multirow[t]{2}{*}{ Meat } & $-0.32 * *$ & $-0.34 * *$ & $-0.47 * * *$ \\
\hline & $(0.16)$ & $(0.16)$ & $(0.18)$ \\
\hline \multicolumn{4}{|l|}{ Crust } \\
\hline \multirow[t]{2}{*}{ Regular } & 0.18 & $0.24 * *$ & $0.52 * * *$ \\
\hline & $(0.10)$ & $(0.11)$ & $(0.13)$ \\
\hline \multirow[t]{2}{*}{ Crispy } & $0.40 * * *$ & $0.38 * * *$ & $0.33^{* * *}$ \\
\hline & $(0.11)$ & $(0.11)$ & $(0.13)$ \\
\hline \multicolumn{4}{|l|}{ Brand } \\
\hline \multirow[t]{2}{*}{ DiGiorno's } & $-0.62 * * *$ & $-0.62 * * *$ & $-0.92 * * *$ \\
\hline & $(0.11)$ & $(0.11)$ & $(0.12)$ \\
\hline \multirow[t]{2}{*}{ California Pizza Kitchen } & $-0.61 * * *$ & $-0.58 * * *$ & $-0.56 * * *$ \\
\hline & $(0.13)$ & $(0.13)$ & $(0.16)$ \\
\hline \multirow[t]{2}{*}{ Freschetta } & $-0.71 * * *$ & $-0.70 * * *$ & -0.52 *** \\
\hline & $(0.12)$ & $(0.12)$ & $(0.14)$ \\
\hline \multirow[t]{2}{*}{ Amy's } & $-0.30 *$ & -0.07 & $-0.61 * * *$ \\
\hline & $(0.17)$ & $(0.20)$ & $(0.23)$ \\
\hline \multirow[t]{2}{*}{ Newman's } & 0.05 & 0.07 & 0.29 \\
\hline & $(0.15)$ & $(0.15)$ & $(0.17)$ \\
\hline
\end{tabular}

Chain,quarter and year dummy variables along with other interactions variables not reported for conciseness. Standard errors are in parantheses, ${ }^{* * *} p<0.01,{ }^{* *} p<0.05,{ }^{*} p<0.1$ 
Table A.13: Demand Results - Poughkeepsie Market

\begin{tabular}{|c|c|c|c|c|}
\hline Coefficients & Logit_OLS & Logit_IV & Random Coefficients & Heterogeneity $(\sigma)$ \\
\hline Price & $\begin{array}{c}-0.12^{* * *} \\
(0.03)\end{array}$ & $\begin{array}{c}-0.14 \text { *** } \\
(0.04)\end{array}$ & $\begin{array}{c}-0.17 \text { *** } \\
(0.04)\end{array}$ & $\begin{array}{c}-0.03 * * * \\
(0.00)\end{array}$ \\
\hline \multicolumn{5}{|l|}{ Topping } \\
\hline Size & $\begin{array}{c}0.03^{* * *} \\
(0.01)\end{array}$ & $\begin{array}{c}0.03 * * * \\
(0.01)\end{array}$ & $\begin{array}{c}0.01 \\
(0.01)\end{array}$ & $\begin{array}{c}-0.05 * * * \\
(0.00)\end{array}$ \\
\hline Exotic & $\begin{array}{c}0.52^{* * *} \\
(0.11)\end{array}$ & $\begin{array}{c}0.52^{* * *} \\
(0.11)\end{array}$ & $\begin{array}{c}0.52 * * * \\
(0.11)\end{array}$ & $\begin{array}{c}0.09 * * * \\
(0.02)\end{array}$ \\
\hline Cheese & $\begin{array}{l}0.17 * * \\
(0.07)\end{array}$ & $\begin{array}{l}0.18 * * \\
(0.07)\end{array}$ & $\begin{array}{l}0.17^{* *} \\
(0.07)\end{array}$ & \\
\hline Vegeatables & $\begin{array}{c}-0.14 \\
(0.08)\end{array}$ & $\begin{array}{c}-0.14 \\
(0.08)\end{array}$ & $\begin{array}{l}-0.15^{*} \\
(0.08)\end{array}$ & \\
\hline Fruit & $\begin{array}{l}0.50 * * \\
(0.24)\end{array}$ & $\begin{array}{l}0.52 * * \\
(0.24)\end{array}$ & $\begin{array}{c}0.45 * \\
(0.24)\end{array}$ & \\
\hline Pepporoni & $\begin{array}{c}0.01 \\
(0.10)\end{array}$ & $\begin{array}{c}0.00 \\
(0.10)\end{array}$ & $\begin{array}{c}-0.01 \\
(0.10)\end{array}$ & \\
\hline Sausage & $\begin{array}{c}-0.47^{* * *} \\
(0.11)\end{array}$ & $\begin{array}{c}-0.46^{* * *} \\
(0.11)\end{array}$ & $\begin{array}{c}-0.49 * * * \\
(0.11)\end{array}$ & \\
\hline Meat & $\begin{array}{c}-0.61 * * * \\
(0.12)\end{array}$ & $\begin{array}{c}-0.60 * * * \\
(0.12)\end{array}$ & $\begin{array}{c}-0.61 * * * \\
(0.12)\end{array}$ & \\
\hline Crust & & & & \\
\hline Regular & $\begin{array}{c}0.15 \\
(0.10)\end{array}$ & $\begin{array}{c}0.15 \\
(0.10)\end{array}$ & $\begin{array}{c}0.18 * \\
(0.10)\end{array}$ & \\
\hline Crispy & $\begin{array}{c}0.44 * * * \\
(0.11)\end{array}$ & $\begin{array}{c}0.36^{* * *} \\
(0.11)\end{array}$ & $\begin{array}{c}0.38 \text { *** } \\
(0.11)\end{array}$ & \\
\hline rand & & & & \\
\hline DiGiorno's & $\begin{array}{c}0.00 \\
(0.10)\end{array}$ & $\begin{array}{c}-0.02 \\
(0.10)\end{array}$ & $\begin{array}{c}-0.03 \\
(0.10)\end{array}$ & \\
\hline California Pizza Kitchen & $-0.40^{* * *}$ & $-0.34 * * *$ & $-0.34 * * *$ & \\
\hline
\end{tabular}




$$
(0.12) \quad(0.12) \quad(0.12)
$$

Freschetta

$$
\begin{array}{lll}
-0.11 & -0.09 & -0.05
\end{array}
$$

\begin{tabular}{lccc} 
& $(0.10)$ & $(0.10)$ & $(0.10)$ \\
Amy's & $-0.51 * * *$ & $-0.36 * *$ & $-0.37 * *$ \\
& $(0.15)$ & $(0.17)$ & $(0.17)$ \\
Newman's & $-0.53 * * *$ & $-0.49 * * *$ & $-0.50 * * *$ \\
& $(0.13)$ & $(0.14)$ & $(0.14)$ \\
\hline \hline
\end{tabular}

Chain,quarter and year dummy variables along with other interactions variables not reported for conciseness. Standard errors are in parantheses, ${ }^{* * *} p<0.01,{ }^{* *} p<0.05,{ }^{*} p<0.1$

Table A.14: BLP estimates, cost parameters for Baltimore Market

\begin{tabular}{lc}
\hline \hline Coefficients & Marginal Costs \\
\hline
\end{tabular}

Price

\section{Topping}

Fruit

$$
-0.80 * * *
$$

Meat

0.17

Vegetable

$-0.20$

Cheese

$-0.15$

Sausage

$-0.23$

\section{Crust}

Regular

$-1.95^{* * *}$

Crispy

0.14

(0.12) 


$\begin{array}{lc}\text { Size } & 0.06^{* * *} \\ & (0.01) \\ \text { Brand } & \\ \text { DiGiorno's } & 2.71^{* * *} \\ & (0.15) \\ \text { California Pizza Kitchen } & 2.27^{* * *} \\ & (0.19) \\ \text { Freschetta } & 2.22^{* * *} \\ & (0.17) \\ \text { Amy's } & 4.11^{* * *} \\ & (0.22) \\ \text { Newman's } & 2.86^{* * *} \\ & (0.25) \\ \text { Kashi } & 3.07^{* * *}\end{array}$

(0.24)

Cost estimates from Baltimore geographic market. Chain dummy variables and other interactions variables not reported for conciseness. Standard errors are in parantheses, ${ }^{* * *} p<0.01,{ }^{* *} p<0.05,{ }^{*}$ $p<0.1$

Table A.15: Inequalities Analysis Results

\begin{tabular}{l|cc}
\hline \hline & Coef & $95 \%$ CI \\
\hline Per SKU: & & \\
Constant & 2.68 & {$[2.1,4.09]$} \\
Avg. Store Size & 72.20 & {$[54.15,174.18]$} \\
& & \\
Category Captain & -0.29 & {$[-0.38,-0.14]$} \\
& & \\
Category Captain*Avg. Store Size & -64.40 & {$[-80.50,-100.85]$}
\end{tabular}




\section{Penalty Constraint}

400

[300.01, 532.35]

Coefficients represent predicted costs to store per product (SKU). Category Captain is an indicator variable for when store is managed by category captains. Penalty constraint captures the soft constraint imposed by the retailer. 
Table A.16: Counterfactual Analysis for Baltimore Market

\begin{tabular}{|c|c|c|c|c|}
\hline & \multicolumn{4}{|c|}{ Category Arrangement } \\
\hline & \multicolumn{2}{|c|}{ Retailer-CC } & \multicolumn{2}{|c|}{ Firm A-CC } \\
\hline & \# of SKUS & $\operatorname{Profits}(\$)$ & \# of SKUS & $\operatorname{Profits}(\$)$ \\
\hline Assortment Superset & 15 & & 15 & \\
\hline Assortment Carried & 10 & & 14 & \\
\hline Retailer & & 41,295 & & 98,096 \\
\hline Firm A & 5 & 29,608 & 10 & 40,411 \\
\hline Firm B & 5 & 59,748 & 4 & 49,679 \\
\hline $\begin{array}{l}\text { Producer Surplus } \\
\text { Consumer Surplus }\end{array}$ & & 130,651 & & $\begin{array}{c}188,186 \\
8,982\end{array}$ \\
\hline
\end{tabular}

The above table shows the results from counterfactual analysis of 2 scenarios- a) when retailer is managing the category and, b) when Firm A is managing the category. The analysis was done on data from a chain in the Baltimore market with 15 products, 5 of which belonged to Firm A and 10 belonged to Firm B 


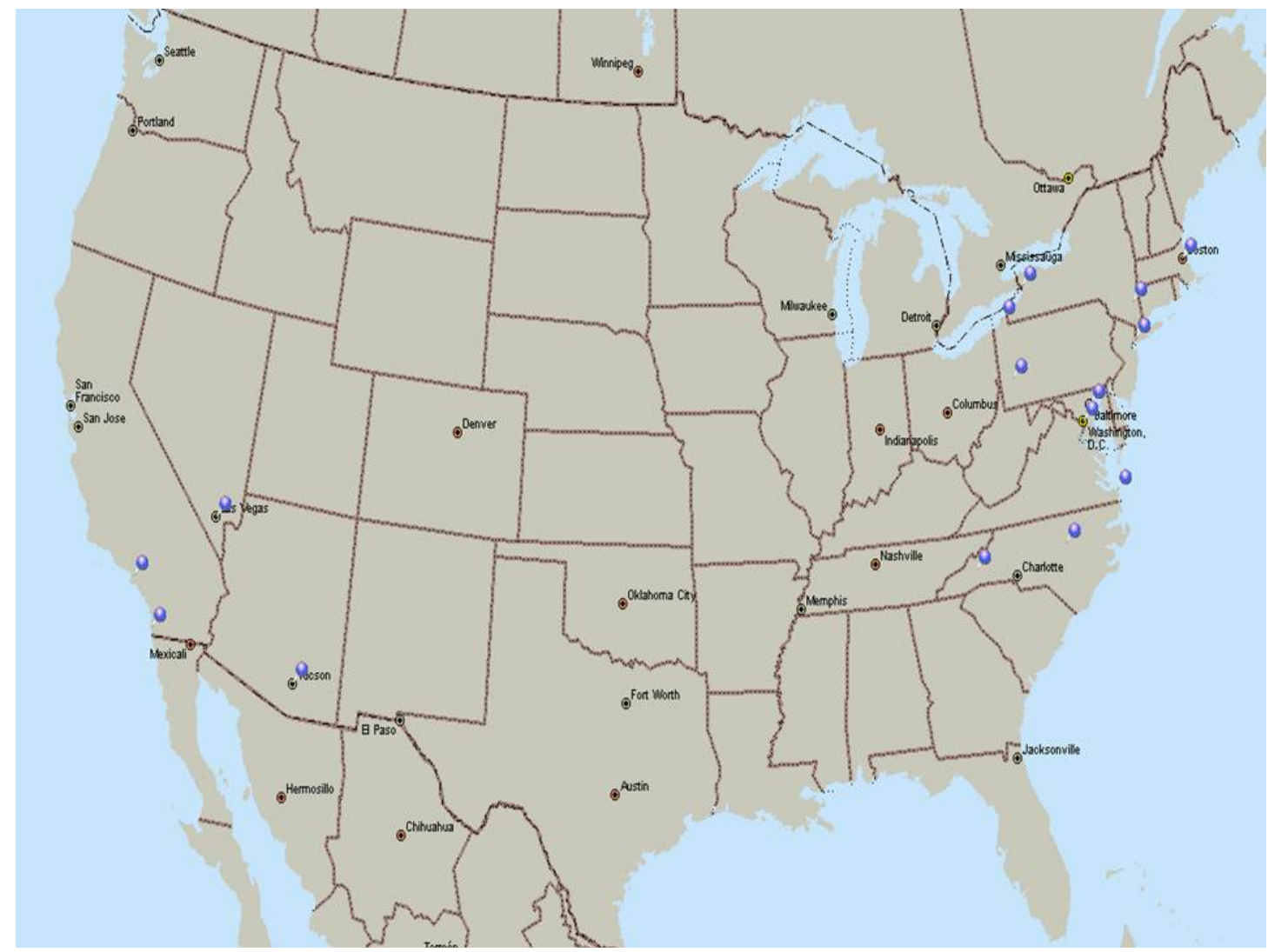

The above map displays the geographic distribution of MSAs that I use for my analysis Figure A.1: Distribution of MSAs 


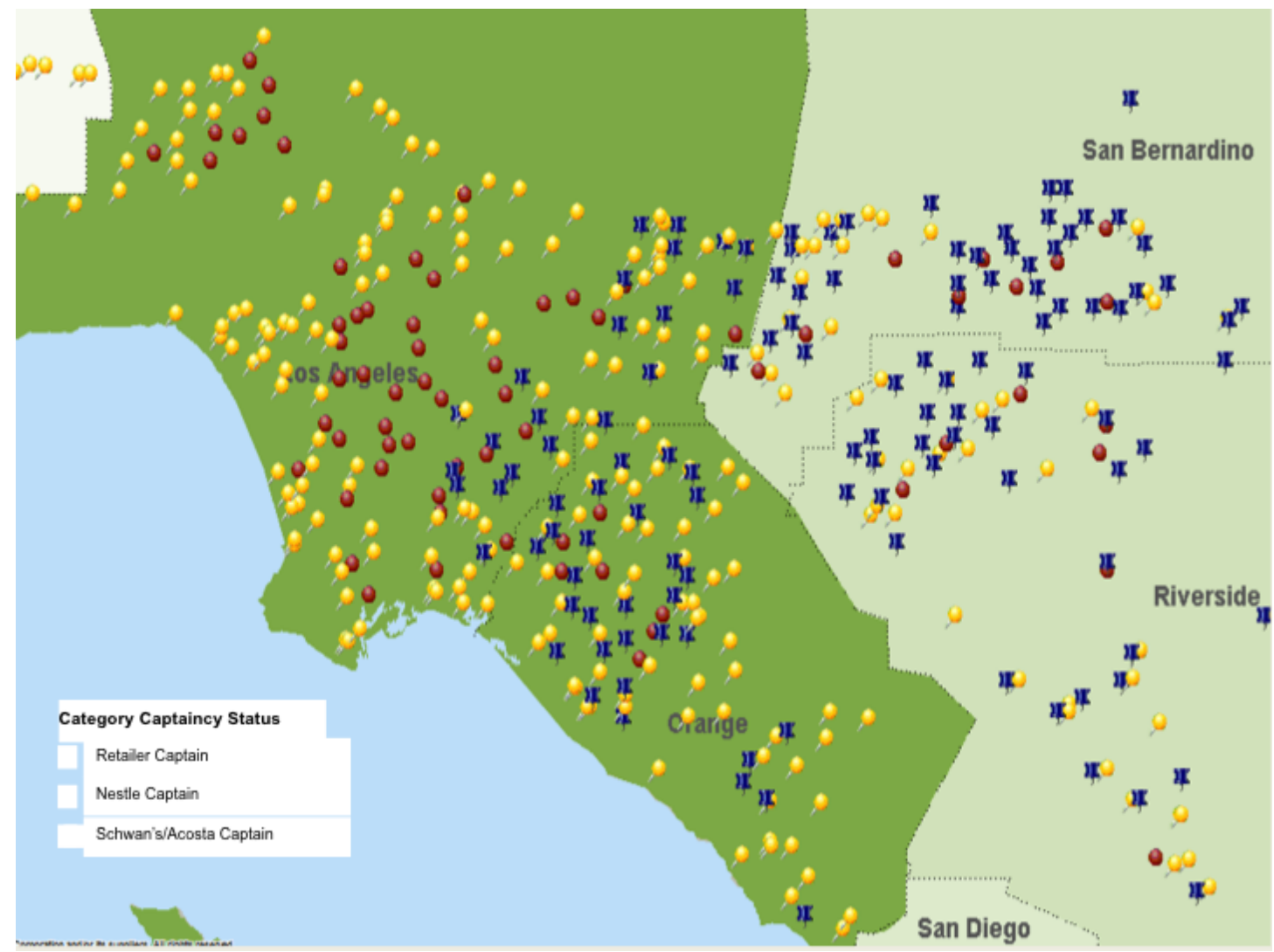

The above map displays the geographic distribution of chains by captaincy in the LA Metropolitan Statistical Area. Note that the MSA has a fair distribution of both chains with captaincy and without. Other MSAs have similar distribution

Figure A.2: Distribution of captaincy 
Size (SELLING SPACE)

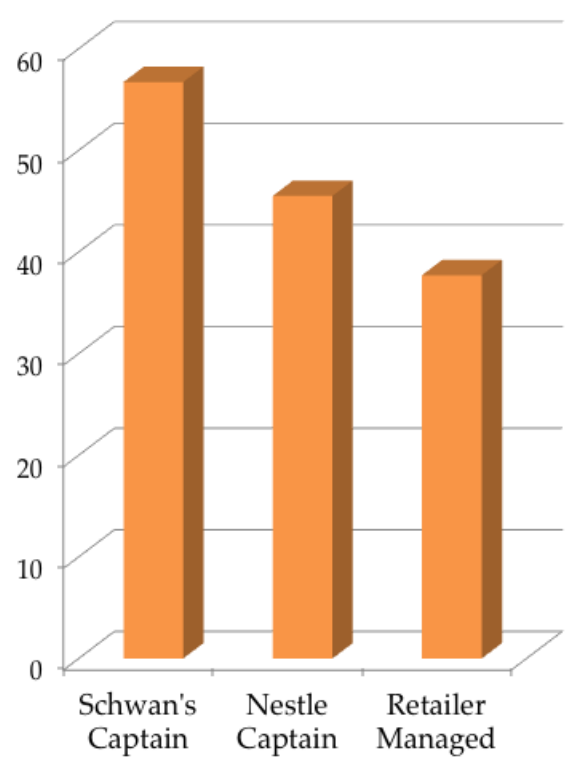

Size (Neilsen Score)

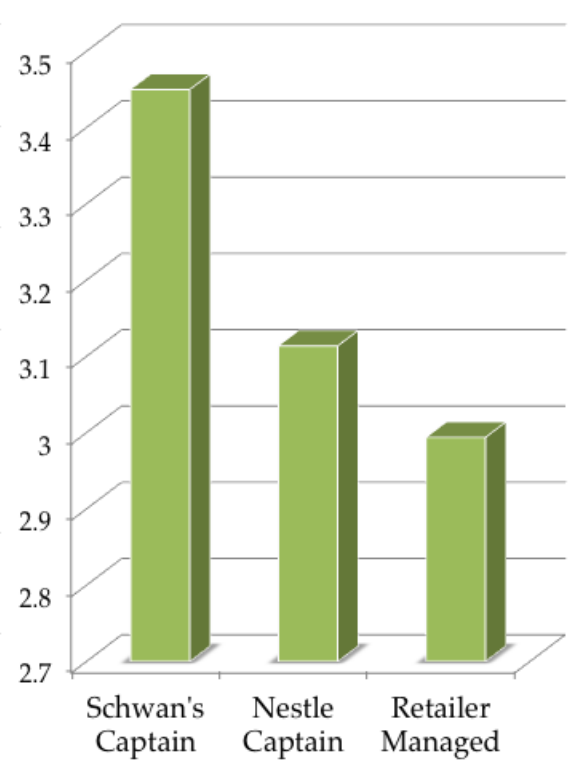

I use two measure of chain size - average selling space of chains and a Nielson based measure of store size. In both cases, a higher number indicates a bigger store.

Figure A.3: Distribution of captaincy by chain size 


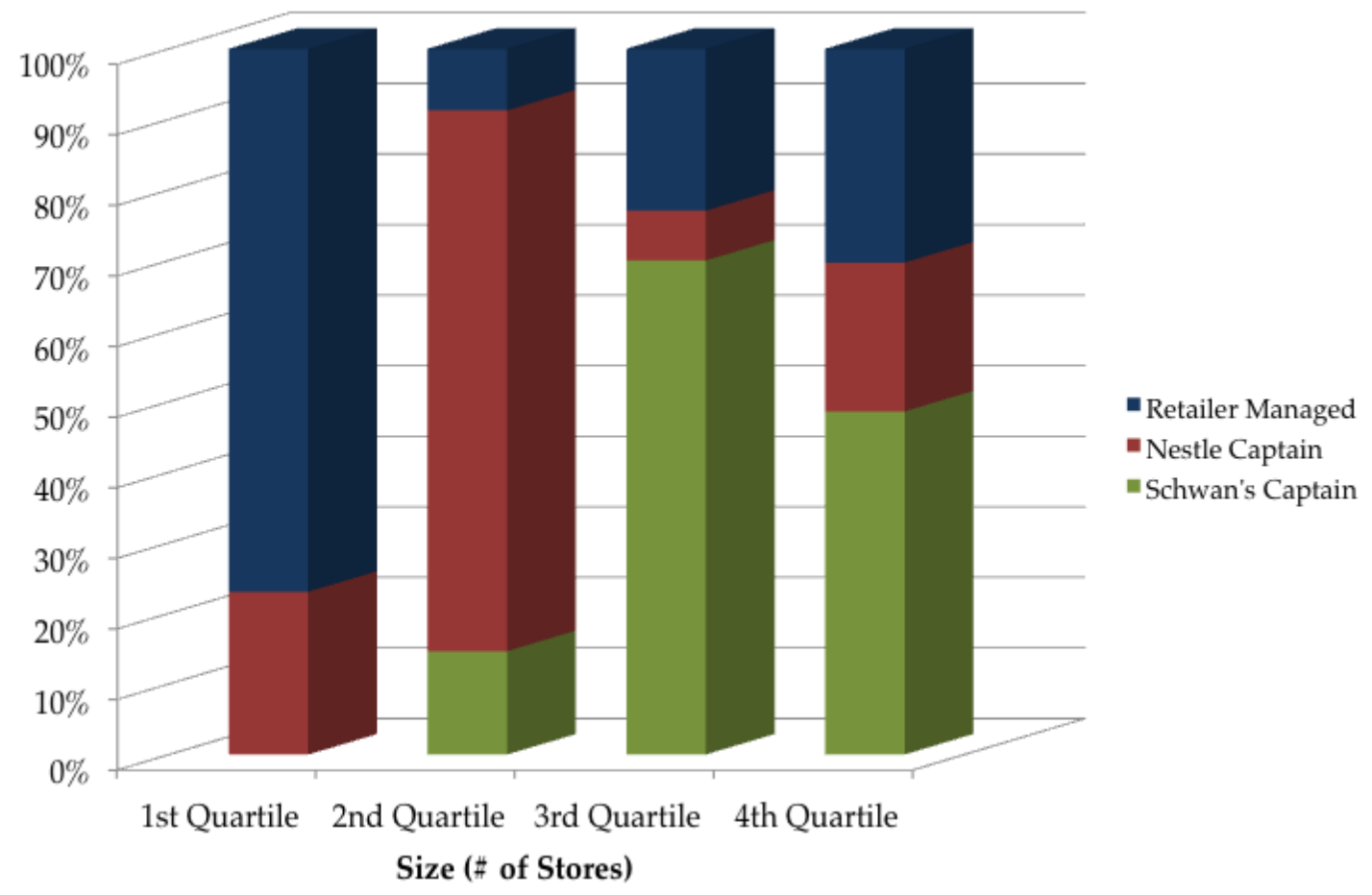

The above measure indicates chain size based on the total number of stores belonging to a chain.

Figure A.4: Distribution of captaincy by chain size 


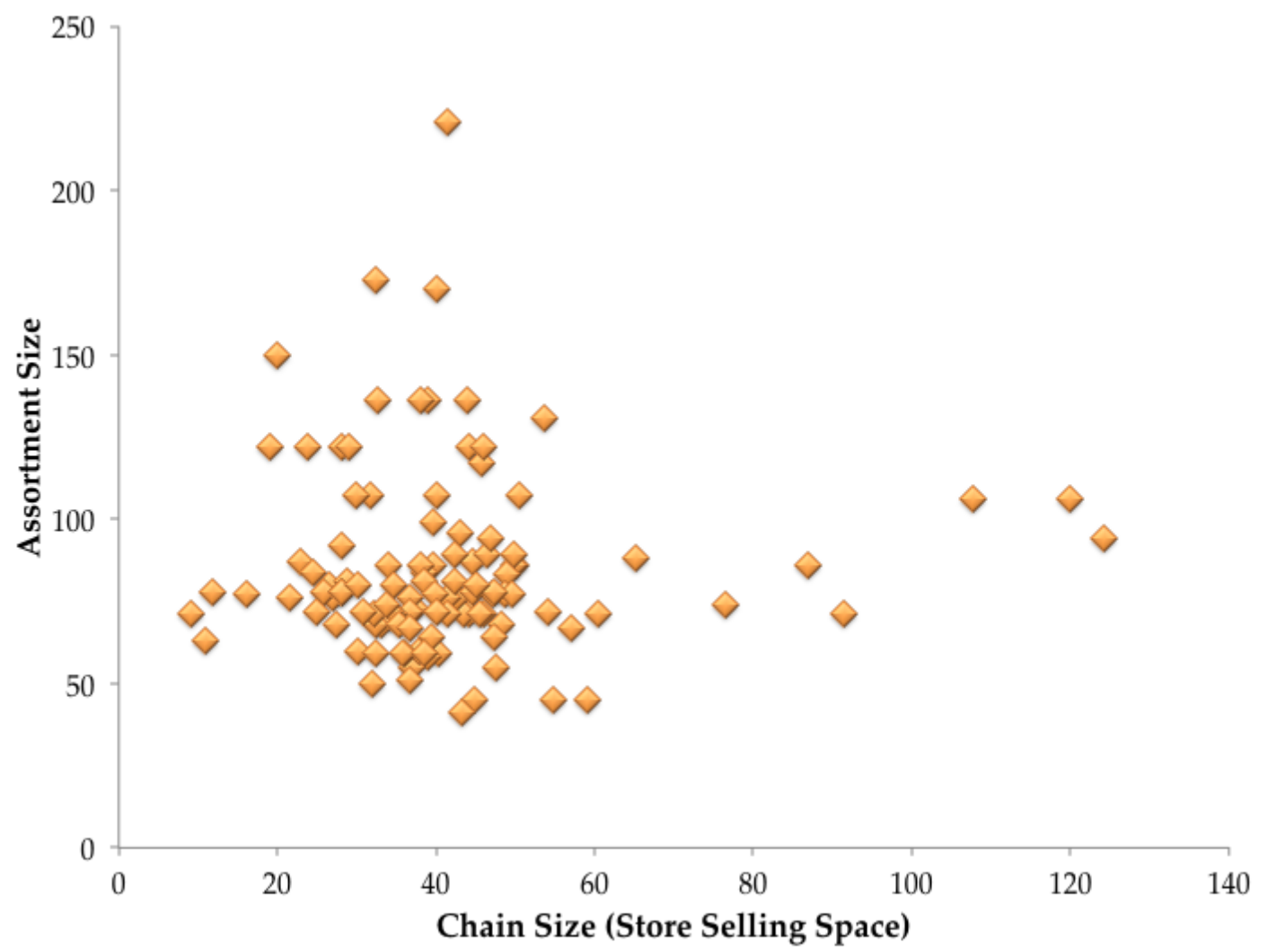

Figure A.5: Distribution of captaincy by chain size 


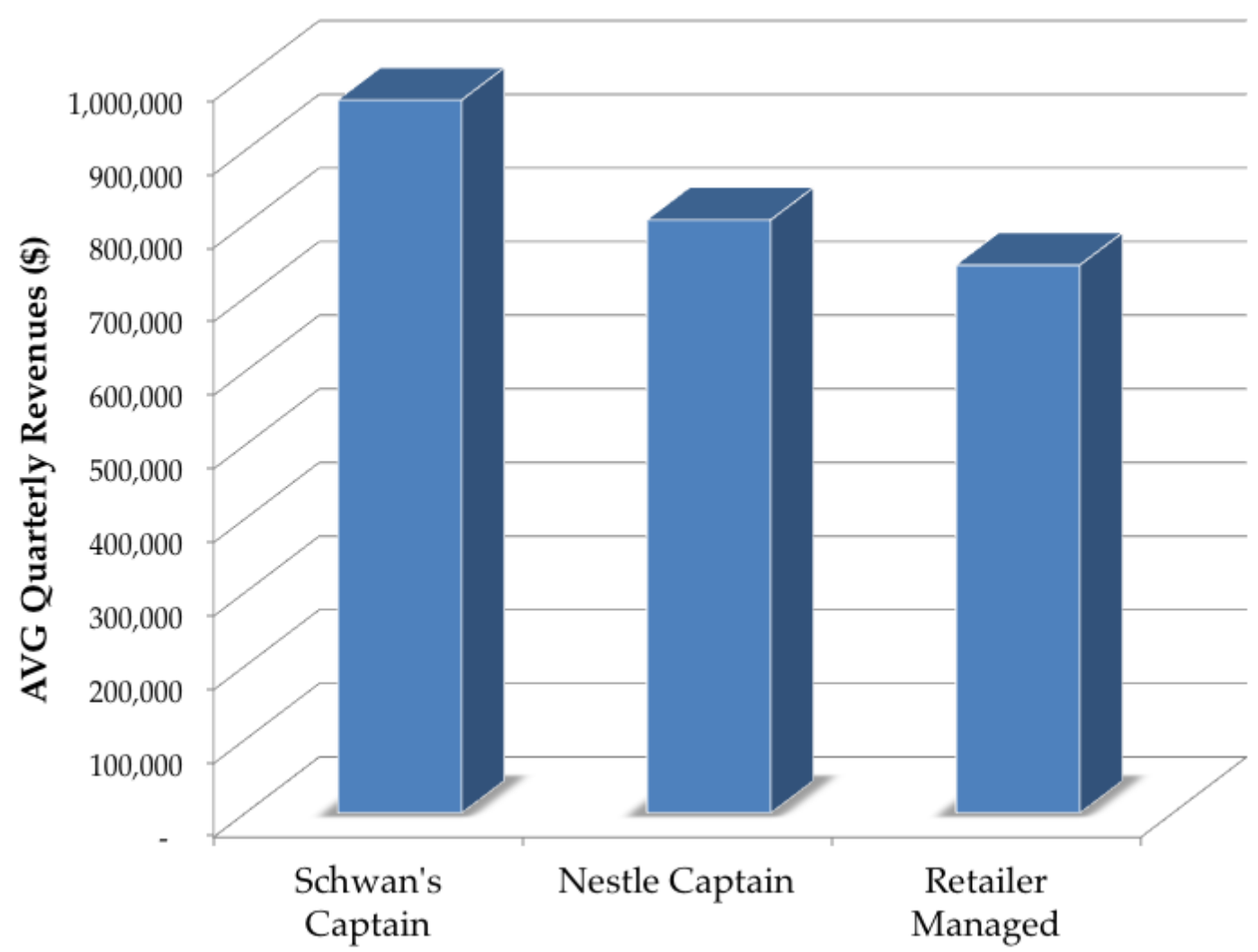

Note that chains with captaincy on average have more revenue than chains without

Figure A.6: Chain Revenues by captaincy 


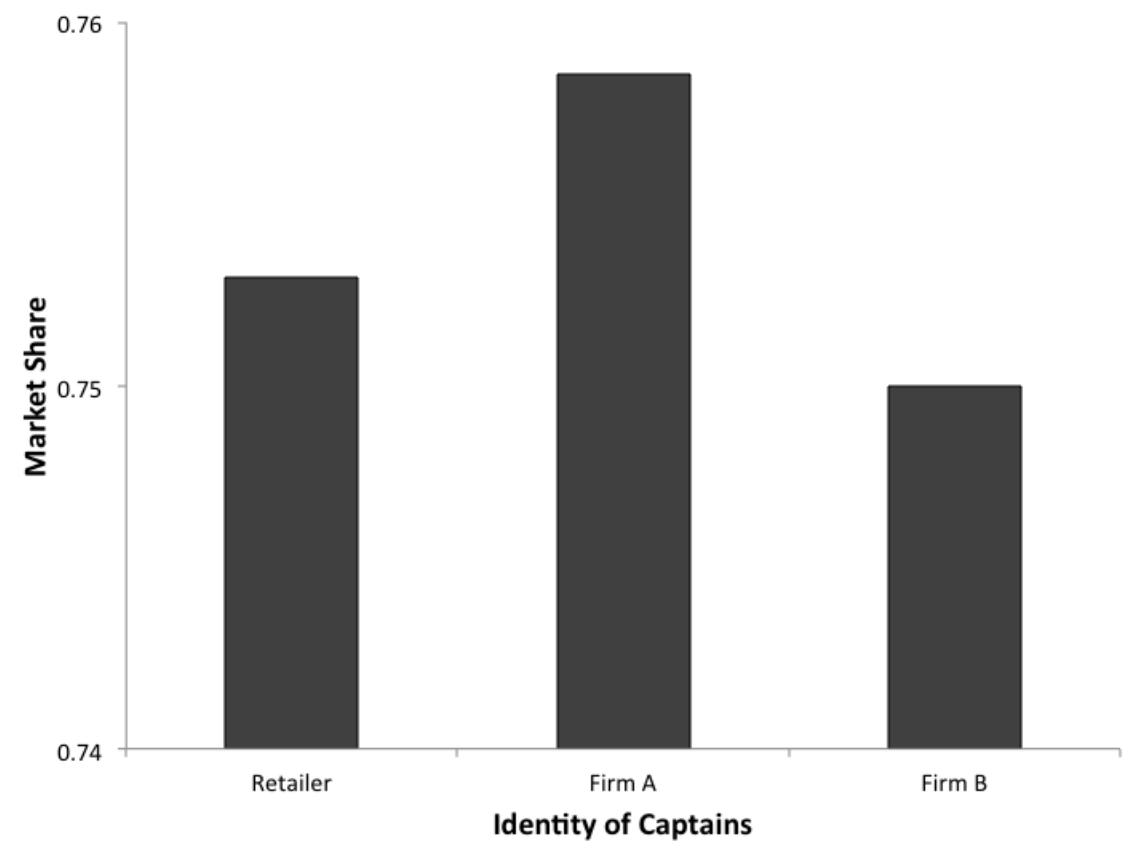

(a) Distribution of Firm A's Market Shares

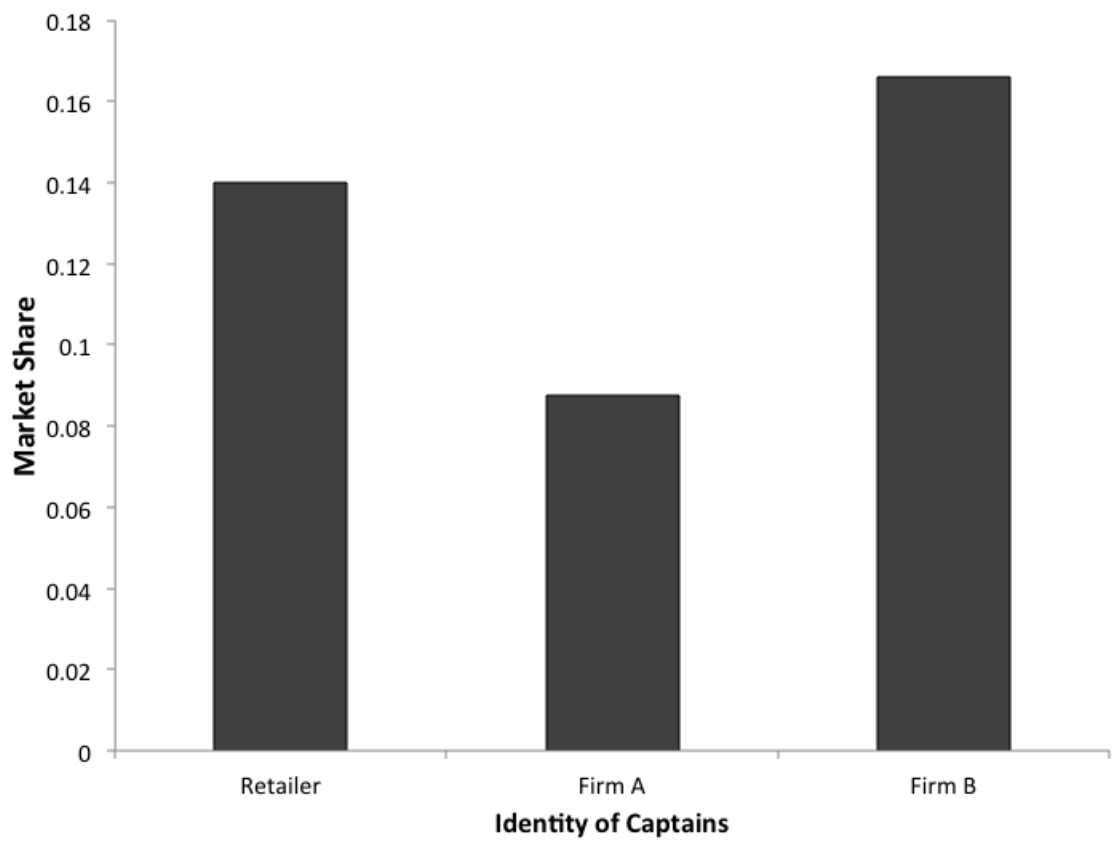

(b) Distribution of Firm B's Market Shares

The figure illustrates the distribution of market shares across different category captains. Market share for each firm is defined as the ratio of total firm sales by total chain sales. Note that Firm A's market shares drop under Firm B's captaincy and vice versa.

Figure A.7: Distribution of Market shares 


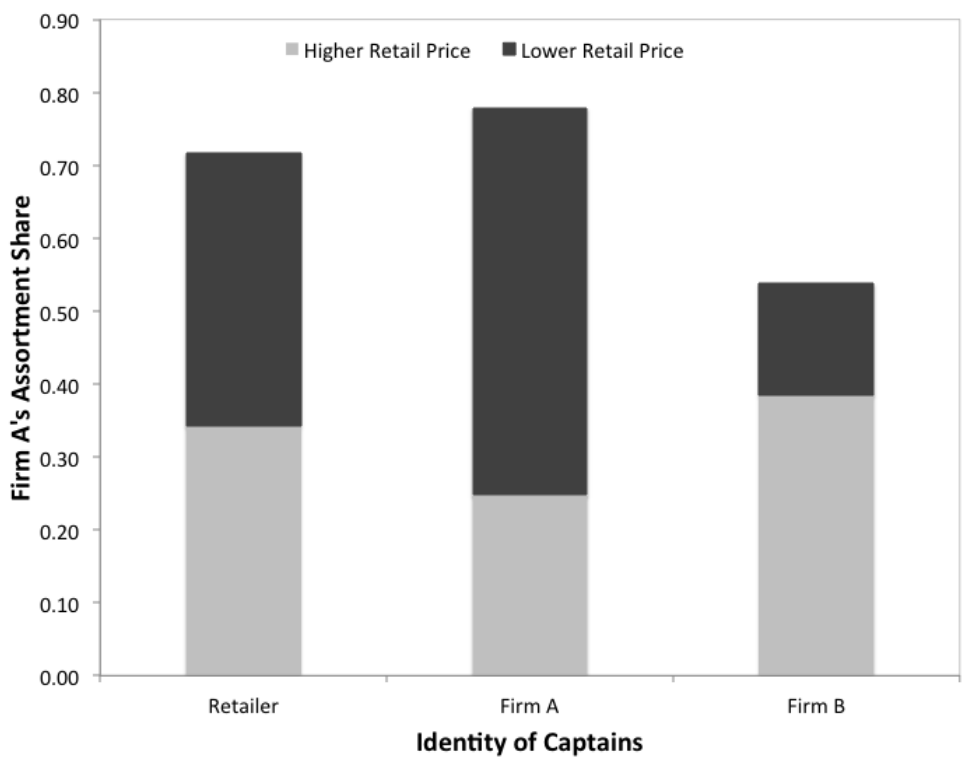

(a) Distribution of Firm A's Assortment Shares

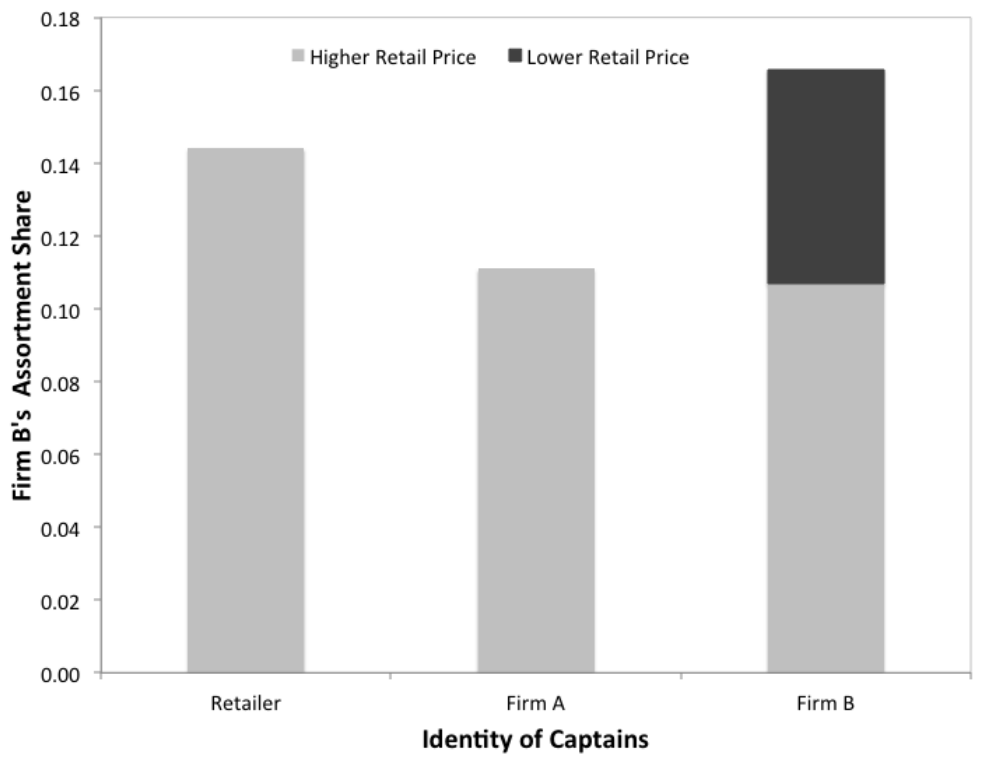

(b) Distribution of Firm B's Assortment Shares

The figure illustrates the distribution of overall assortment shares across different category captains. SKUs are split into "Higher" and "Lower" Retail Price SKUs. Notice that captaincy increases assortment shares of the captain's SKUs particularly that of lower priced SKUs.

Figure A.8: Distribution of Assortment shares 